\title{
Hydrogen effects on the thermal conductivity of delocalized vibrational modes in amorphous silicon nitride $\left(a-\mathrm{SiN}_{x}: \mathrm{H}\right)$
}

\author{
Jeffrey L. Braun, ${ }^{1}$ Sean W. King $\odot,{ }^{2, *}$ Eric R. Hoglund, ${ }^{3}$ Mehrdad Abbasi Gharacheh $\odot,{ }^{4}$ Ethan A. Scott $\odot,{ }^{1}$ Ashutosh Giri $\odot,{ }^{1,5}$ \\ John A. Tomko $\odot,{ }^{3}$ John T. Gaskins $\odot,{ }^{1}$ Ahmad Al-kukhun, ${ }^{2}$ Gyanendra Bhattarai, ${ }^{6}$ Michelle M. Paquette, ${ }^{6}$ \\ Georges Chollon $\odot,{ }^{7}$ Benjamin Willey $\odot,{ }^{8}$ G. Andrew Antonelli $\odot,{ }^{8}$ David W. Gidley, ${ }^{9}$ Jinwoo Hwang, ${ }^{4}$ \\ James M. Howe, ${ }^{3}$ and Patrick E. Hopkins (10 ${ }^{1,3,10, \dagger}$ \\ ${ }^{1}$ Department of Mechanical and Aerospace Engineering, University of Virginia, Charlottesville, Virginia 22904, USA \\ ${ }^{2}$ Intel Corporation, Logic Technology Development, 5200 NE Elam Young Parkway, Hillsboro, Oregon 97124, USA \\ ${ }^{3}$ Department of Materials Science and Engineering, University of Virginia, Charlottesville, Virginia 22904, USA \\ ${ }^{4}$ Department of Materials Science and Engineering, The Ohio State University, Columbus, Ohio 43210, USA \\ ${ }^{5}$ Department of Mechanical, Industrial and Systems Engineering, University of Rhode Island, Kingston, Rhode Island 02881, USA \\ ${ }^{6}$ Department of Physics and Astronomy, University of Missouri-Kansas City, Kansas City, Missouri 64110, USA \\ ${ }^{7}$ Laboratoire des Composites Thermostructuraux, CNRS-SAFRAN Ceramics-CEA-University of Bordeaux, 3, \\ allee de La Boetie, 33600 Pessac, France \\ ${ }^{8}$ Onto Innovation, Portland, Oregon 97202, USA \\ ${ }^{9}$ Department of Physics, University of Michigan, Ann Arbor, Michigan 48109, USA \\ ${ }^{10}$ Department of Physics, University of Virginia, Charlottesville, Virginia 22904, USA
}

(Received 9 November 2020; revised 15 February 2021; accepted 25 February 2021; published 23 March 2021)

\begin{abstract}
Hydrogenated amorphous dielectric thin films are critical materials in a wide array of technologies. In this work, we present a thorough investigation of the thermal conductivity of hydrogenated amorphous silicon nitride $\left(a-\mathrm{SiN}_{x}: \mathrm{H}\right)$, a ubiquitously used material in which the stoichiometry plays a direct role in its functionality and application. In particular, through chemical, vibrational, and structural analysis in tandem with thermal conductivity measurements on chemically variant silicon nitride films, we show that hydrogen incorporation into silicon nitride disrupts the bonding among silicon and nitrogen atoms, and directly impacts the thermal conductivity, leading to as much as a factor of 2.5 variation in heat transfer. This variability, driven by the change in hydrogen content, is fundamentally related to the changes in the average atomic distances, as we experimentally measure with selected-area electron diffraction and computationally show with molecular dynamics simulations. This, combined with our evidence of chemical and spatial fluctuations on the order of average atomic pair distances, leads us to conclude that the vibrational heat transport in $a-\mathrm{SiN}_{x}: \mathrm{H}$ is primarily dominated by diffusonlike modes. The results presented in this work combined with our extensive review of prior reports on the thermal conductivity of $a-\mathrm{SiN}_{x}: \mathrm{H}$ films resolves discrepancies in decades of prior literature and facilitates a more universal understanding of the vibrational heat transport processes in hydrogenated amorphous silicon nitride.
\end{abstract}

DOI: 10.1103/PhysRevMaterials.5.035604

\section{INTRODUCTION}

Hydrogenated amorphous thin films are widely used in the semiconductor industry for a variety of electronic, optoelectronic, photovoltaic, thermal, mechanical, microelectromechanical, and biological applications [1-7]. Amorphous hydrogenated silicon nitride $\left(a-\mathrm{SiN}_{x}: \mathrm{H}\right)$ films, in particular, are widely used for both surface and bulk passivation of silicon and as antireflective coatings to improve solar cell

\footnotetext{
*sean.king@intel.com

†phopkins@virginia.edu
}

Published by the American Physical Society under the terms of the Creative Commons Attribution 4.0 International license. Further distribution of this work must maintain attribution to the author(s) and the published article's title, journal citation, and DOI. efficiency [8-14]. The higher refractive indices in these films, and their tunability based on stoichiometry, make $a-\mathrm{SiN}_{x}: \mathrm{H}$ films highly appealing for selective antireflective coatings compared with alternative thermal oxide layers [10]. Beyond solar cell applications, $a-\mathrm{SiN}_{x}: \mathrm{H}$ films also find use as gate dielectrics for insulation in amorphous hydrogenated silicon $(a$-Si:H)-based and organic thin-film-based transistors $[15,16]$, heterojunction bipolar transistor technology [17], as well as liquid-crystal display (LCD) and other newly emerging display technologies [2].

Despite its ubiquity in these application areas, a thorough investigation of the thermal properties of $a-\mathrm{SiN}_{x}: \mathrm{H}$ has remained unexplored. In particular, because stoichiometry and hydrogen composition control the physical properties of this material [18], a systematic study of the role of $\mathrm{Si}, \mathrm{N}$, and $\mathrm{H}$ composition on the thermal conductivity of $a-\mathrm{SiN}_{x}: \mathrm{H}$ thin films would greatly benefit the prediction and modeling of heat transfer in devices reliant on these films. Considering 
the aforementioned application space, the thicknesses of $a$ $\mathrm{SiN}_{x}: \mathrm{H}$ films can vary between a few nanometers to several microns. Thus, in this work we investigate the role of film thickness, composition, and hydrogenation on the thermal conductivity of plasma-enhanced chemical vapor deposition (PECVD)-grown $a$-SiN $x$ :H films to show how thermal conductivity can be systematically reduced through increasing hydrogen content; in fact, no matter the ratio of $\mathrm{Si}$ and $\mathrm{N}$, the thermal conductivity is primarily dictated by the atomic percentage of hydrogen $($ at. $\% \mathrm{H})$. We find that for our specific PECVD films, the growth conditions restrict the lower-bound of achievable hydrogen content. Thus, to further reduce the at. $\% \mathrm{H}$ in these materials, we anneal the samples at four temperatures ranging from $650{ }^{\circ} \mathrm{C}$ to $1000{ }^{\circ} \mathrm{C}$ to remove hydrogen through chemical dissociation [19]. Between the as-deposited and annealed films, the composition of our PECVD-grown $a-\mathrm{SiN}_{x}: \mathrm{H}$ films range from $0-26$ at. $\% \mathrm{H}$ with at. $\% \mathrm{~N}:$ at. $\%$ Si ratios ranging from $0.45-1.41$.

This extensive study of the role of thickness and composition on the thermal conductivity of $a-\mathrm{SiN}_{x}: \mathrm{H}$ also allows us to further understand the fundamental vibrational mechanisms that drive thermal transport in $a$-SiN $x$. In amorphous solids, the vibrational modes contributing to thermal transport consist of localized, nonpropagating modes called locons, delocalized, nonpropagating modes called diffusons, and delocalized, propagating modes called propagons [20]. For propagating modes, the eigenvectors associated with each vibrational mode have a preferred direction and a well-defined periodicity, which is in contrast to modes described as diffusons and locons. While locons are highly localized, diffusons are delocalized over the entire structure. As such, diffuson-mediated heat transfer occurs via the spatial overlap of the delocalized modes. This is quantified by the Allen-Feldman theory [21], where the diffusivity of delocalized modes responsible for heat conduction depends on the spatial overlap of eigenvectors as well as the energetic overlap (or how close the frequencies of the modes are to each other) [22].

Evidence for propagon thermal transport is typically sought through observation of sample size-dependent thermal conductivity, since propagating modes can be suppressed through boundary scattering. A strong contribution to thermal conductivity from propagons, or longer wavelength propagonlike modes, is seemingly rare in amorphous solids, having only been shown conclusively in amorphous silicon [23-27]. While the thermal conductivity of $a-\mathrm{SiN}_{x}$ has been suggested to have a contribution from propagons at room temperature [24], verification of this as a general rule has remained inconclusive. Thus, to selectively study the role of hydrogen on propagon thermal transport, we additionally measure the thermal conductivity of hydrogenated amorphous silicon $(a-\mathrm{Si}: \mathrm{H})$ as a function of film thickness. It is well established that $a-\mathrm{Si}$ can have a large fraction of its thermal conductivity comprised of propagons or other longer wavelength propagonlike modes [23-29], as evidenced by increasing thermal conductivity with increasing sample thickness. The addition of hydrogen to both $a$-Si and $a-\mathrm{SiN}_{x}$ adds the additional complexity of bond termination. Beyond simply mass variation alone, the addition of hydrogen fundamentally reduces the coordination number, defined as the average number of atomic bonds an atom in a material possesses, which we previously showed to have significant influence on the thermal conductivity of $200 \mathrm{~nm}$ films of hydrogenated amorphous silicon, hydrogenated amorphous silicon oxide, and hydrogenated amorphous silicon carbide [30].

In this work, we show that hydrogen incorporation into silicon nitride disrupts the bonding among silicon and nitrogen atoms by first incorporating primarily as $\mathrm{Si}-\mathrm{H}$ bonding, with increased $\mathrm{N}-\mathrm{H}$ bonding at higher hydrogen concentrations. This incorporation of hydrogen leads to an increase in average atomic pair distances, as measured via selected-area electron diffraction, which underpins the resulting decrease in density of the films, and directly translates to a reduction in thermal conductivity. Regardless of the hydrogen content and density, we observe no significant change in thermal conductivity with film thickness for thicknesses ranging from $50 \mathrm{~nm}$ to $2 \mu \mathrm{m}$, ruling out that propagons or other longer wavelength modes with scattering length scales on the order of $50 \mathrm{~nm}$ or greater are contributing to thermal conductivity in $a-\mathrm{SiN}_{x}: \mathrm{H}$ films, and suggesting that the vibrational heat transport in $a-\mathrm{SiN}_{x}: \mathrm{H}$ is primarily dominated by diffusonlike modes at room temperature. The thermal conductivity of the diffusons in $a-\mathrm{SiN}_{x}: \mathrm{H}$ is a direct function of the hydrogen composition, and is proportional to the density and average atomic pair distances in the material. We further support this conclusion through molecular dynamics simulations, and show that an increased density leads to an increased overlap of the diffuson wave functions, leading to the increased diffuson thermal conductivity. The original results presented in this work combined with our extensive review of prior reports on the thermal conductivity of $a-\mathrm{SiN}_{x}: \mathrm{H}$ films resolves discrepancies in prior literature and facilitates a more universal understanding of the vibrational heat transport processes in hydrogenated amorphous silicon nitride.

\section{BACKGROUND AND LITERATURE REVIEW}

While few studies on thermal conductivity of the explicitly defined hydrogenated variant have been reported, amorphous silicon nitride $\left(a-\mathrm{SiN}_{x}\right)$ has been extensively studied due to its application in thermal isolation, surface passivation, etch masking, and as structural or optical layers for various microelectromechanical systems (MEMS) [31,32]. The various references, thermal conductivities, and pertinent deposition and thermophysical properties of $a-\mathrm{SiN}_{x}$ thin films are discussed in context below, with the values tabulated in Tables II and III in the Appendix. The goal of this section is to present these previously measured thermal conductivities of $a-\mathrm{SiN}_{x}$ as a function of film thickness and, if reported, growth (or annealing) temperature, composition based on reported ratio of at. $\% \mathrm{~N}$ to at. $\% \mathrm{Si}$, or mass density. We also differentiate among the $a-\mathrm{SiN}_{x}$ films based on deposition method, which include low-pressure chemical vapor deposition (LPCVD) [33-46], plasma-enhanced chemical vapor deposition (PECVD) [32,47-50], atmospheric pressure chemical vapor deposition (APCVD) [50], chemical vapor deposition (CVD) [51,52], and sputtering [53,54]. We make this differentiation since PECVD-deposited silicon nitride films will contain some level of hydrogen [55], but in these previous reports of the thermal conductivity of PECVD-grown films [32,47-50], the hydrogen composition is neither discussed nor 
(a)

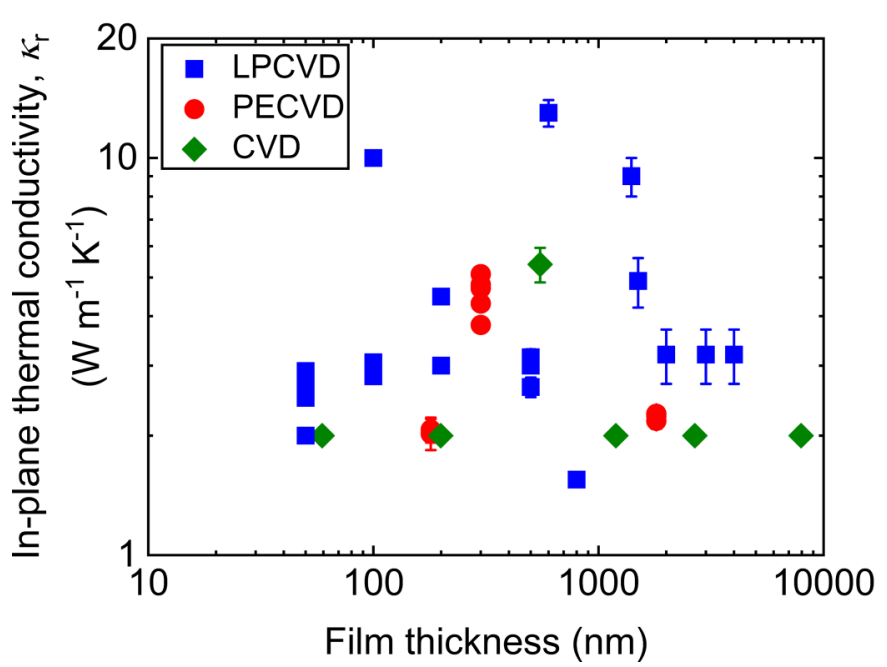

(b)

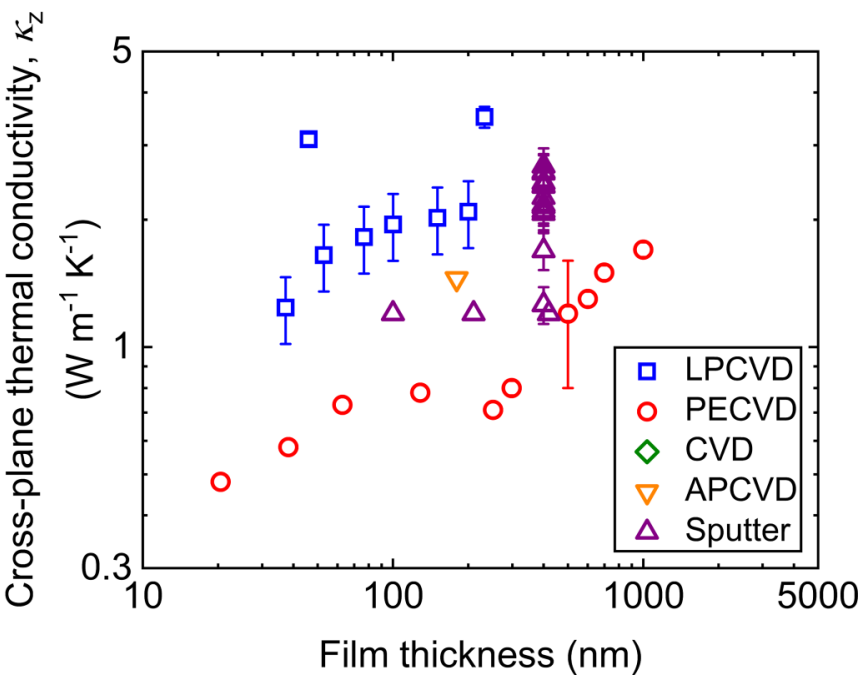

FIG. 1. (a) In-plane thermal conductivity and (b) cross-plane thermal conductivity vs. film thickness for amorphous silicon nitride. The thermal conductivity is shown for Refs. [32-54]. Closed symbols represent in-plane thermal conductivity measurements, while open symbols represent cross-plane thermal conductivity measurements. These data points are tabulated in Tables II and III in the Appendix.

quantified. Thus, in this work, we assume that the previously grown PECVD films have a composition of $a-\mathrm{SiN}_{x}: \mathrm{H}$. We focus this review on previous works reporting on the thermal conductivity of amorphous silicon nitride films, although in one case discussed below, partial crystallinity was posited, and we mention this in our discussion. Due to the variations in deposition methods and measurement techniques, the films reviewed here are a combination of suspended beams or supported films on substrates; we cannot make any assumption on how this boundary condition impacts the reported thermal conductivities of these previously reported films. The literature review in this section will guide the formulation of the major outstanding unanswered questions that have prevented a more complete understanding of the fundamental vibrational heat transfer processes in $a$-SiN $x$, and how and why variable hydrogen composition impacts the thermal conductivity of $a-\mathrm{SiN}_{x}: \mathrm{H}$.

A summary of the previously reported thermal conductivities of amorphous silicon nitride films, provided in Fig. 1 and tabulated in Tables II and III in the Appendix, reveals a wide variation in the reported thermal conductivity, $\kappa$, for $a-\mathrm{SiN}_{x}$ as a function of film thickness, ranging from $\sim 0.5$ to $13 \mathrm{~W} \mathrm{~m}^{-1} \mathrm{~K}^{-1}$ at room temperature. While conventional wisdom suggests the thermal conductivity of amorphous materials is isotropic, Kwon et al. [25] used $a$-Si to show that this is not always the case. Therefore, it is important to emphasize the direction of $\kappa$ reported (in-plane, $\kappa_{\mathrm{r}}$, which is parallel to the limiting dimension, or cross-plane, $\kappa_{\mathrm{z}}$, which is perpendicular to the limiting dimension). The majority of reported measurements on thermal conductivity have been conducted on suspended films and membranes, such that $\kappa_{\mathrm{r}}$ is fundamentally measured. In Fig. 1 we distinguish between previously reported values of in-plane thermal conductivities $[32-44,47,51,52]$ and cross-plane thermal conductivities $[45,46,48-50,53,54]$ by plotting $\kappa_{\mathrm{r}}$ versus film thickness $(d)$ in Fig. 1(a) and $\kappa_{\mathrm{z}}$ versus $d$ in Fig. 1(b).
An immediate empirical conclusion that can be drawn from the trends in Figs. 1(a) and 1(b) is that while there is no apparent trend in thermal conductivity versus $d$ in the in-plane direction, there could be a size effect driving the trends in the cross-plane thermal conductivity versus $d$, depending on the deposition method. It is important to note, however, that Lee and Cahill [50] explained this trend in their $\kappa_{\mathrm{z}}$ versus $d$ data on their PECVD-grown films by considering a thermal boundary resistance [56-58] at the films' interfaces that impacted their $3 \omega$ measurements [59] by introducing additional thermal resistances in series with the intrinsic thermal conductivity of the amorphous silicon nitride. Thus, the $\kappa_{z}$ values reported for $a-\mathrm{SiN}_{x}: \mathrm{H}$ by Lee and Cahill [50] were in fact effective thermal conductivities that included the impact of the thermal boundary resistances, and thus their work could suggest that the intrinsic cross-plane thermal conductivity of PECVD-grown $a$-SiN $x$ :H films should not exhibit any intrinsic size effects. This is supported by measurements of $\kappa_{z}$ of LPCVD-grown $a$-SiN $x$ films for two different thicknesses ( $d=46$ and $232 \mathrm{~nm}$ ) by Hopkins et al. [45] using time-domain thermoreflectance (TDTR) [60,61]. TDTR is well established to be able to separate the contributions of thermal boundary resistances from intrinsic thermal conductivities of thin films when measuring the cross-plane thermal properties of thin film composites [45] (assuming suitable thicknesses and thermal conductivities of the thin films $[62,63])$. The thermal conductivities of the LPCVD-grown $a$-SiN $x$ film reported by Hopkins et al. [45] are not only relatively constant for the two thicknesses, but also higher than other previous reports of $\kappa_{z}$ for amorphous silicon nitride films shown in Fig. 1(b). While this could be explained by the aforementioned thermal boundary resistances, other factors leading to discrepancies in these cross-plane data are the differing growth conditions, changes in mass densities, and different stoichiometries. This example is but one of many inconsistencies among the various data presented in Figs. 1(a) and 1(b). In general, we find 
that due to the wide variability in the thermal conductivity of amorphous silicon nitride based on different deposition techniques, additional considerations beyond film thickness must be dictating the thermal conductivity of $a-\mathrm{SiN}_{x}$ thin films. We discuss each of these prior works in more detail below.

We begin this detailed discussion with the in-plane thermal conductivity data in Fig. 1(a). Mastrangelo et al. [33] first measured $\kappa_{\mathrm{r}}$ of low-stress, LPCVD-grown $\mathrm{Si}_{1.0} \mathrm{~N}_{1.1}$ microbridges ranging in thickness from 2 to $4 \mu \mathrm{m}$ to be $3.2 \mathrm{~W}$ $\mathrm{m}^{-1} \mathrm{~K}^{-1}$ with no dependence on thickness; we note that Mastrangelo et al. [33] did not report on whether these films were amorphous or not. Griffin et al. [51] later measured $\kappa_{\mathrm{r}}$ for CVD-grown amorphous $\mathrm{Si}_{3} \mathrm{~N}_{4}$ using a steady-state technique to be $\sim 2 \mathrm{~W} \mathrm{~m}^{-1} \mathrm{~K}^{-1}$ and independent of thickness for films ranging in thicknesses from 0.06 to $8 \mu \mathrm{m}$. Zhang and Grigoropoulos [40] used three experimental methods-the phase-shift method, the amplitude method, and the heat-pulse method-to determine $\kappa_{\mathrm{r}}$ for a Si-rich $\mathrm{SiN}_{x}$ film $(66.8 \%$ $\mathrm{Si}$ and $33.2 \% \mathrm{~N}$ in atomic weight) deposited via LPVCD; they found $\kappa_{\mathrm{r}}$ to be 9 and $13 \mathrm{~W} \mathrm{~m}^{-1} \mathrm{~K}^{-1}$ for the 1.4 and $0.6 \mu \mathrm{m}$ film, respectively, where the reduced thermal conductivity of the thicker film was postulated to be due to a higher density of voids. These data reported by Zhang and Grigoropoulos are the highest values for amorphous silicon nitride thermal conductivity reported to date. However, given the $\mathrm{Si}$ composition and growth temperature, we cannot rule out the possibility of local crystallization of the $\mathrm{Si}$, which could explain these high values; note, film microstructure was not reported in this work. Irace and Sarro [41] used a resistor heating and thermocouple-based technique to measure $\kappa_{\mathrm{r}}$ of a 800-nm-thick, low-stress LPCVD-grown $\mathrm{SiN}_{x}$ membrane to be $1.55 \mathrm{~W} \mathrm{~m}^{-1} \mathrm{~K}^{-1}$, the lowest value of $\kappa_{\mathrm{r}}$ yet reported. However, Zink and Hellman [34] later used a membrane-based microcalorimeter technique to measure $\kappa_{\mathrm{r}}$ of a LPCVD-grown 200-nm-thick low-stress amorphous $\mathrm{SiN}_{x}$ membrane to be $\sim 3 \mathrm{~W} \mathrm{~m}^{-1} \mathrm{~K}^{-1}$ at room temperature, in agreement with the measurement by Mastrangelo et al. [33] despite an order of magnitude reduction in thickness. Eriksson et al. [32] used an electrical-based resistive heater and temperature sensor method to measure $\kappa_{\mathrm{r}}$ on a series of 300and 500-nm-thick $\mathrm{SiN}_{x}: \mathrm{H}$ membranes (reported as $a$-SiN). They reported variations in their measured thermal conductivities among the five measurements ranging from $3.8-5.1 \mathrm{~W}$ $\mathrm{m}^{-1} \mathrm{~K}^{-1}$ with no systematic trend in film thickness. While the authors discussed potential artifacts and uncertainties in their measurements due to heat flux losses and temperature coefficient of resistance calibrations, they also point out that the measured heat capacities per unit mass in each of their films are different, which could indicate changes in stoichiometry, consistent with our discussion above regarding the hydrogen compositions in PECVD grown films. As with all other works studying the thermal conductivity of PECVDgrown amorphous silicon nitride thin films discussed here, the hydrogen content in their films was neither discussed nor quantified. Similarly, Stojoanovic et al. [47] used a resistive heater and resistance-based temperature detector to determine $\kappa_{\mathrm{r}}$ of PECVD-grown, 180-nm-thick $\mathrm{SiN}_{x}: \mathrm{H}$ membranes (reported as $\mathrm{SiN}_{x}$ ) to be $\sim 2 \mathrm{~W} \mathrm{~m}^{-1} \mathrm{~K}^{-1}$, lower than the values reported by Eriksson et al. [32] but for a thinner membrane, but again, hydrogen content in these PECVD-grown films was ignored. However, shortly after, Jain and Goodson [37] used the $3 \omega$ method to determine $\kappa_{\mathrm{r}}$ for a LPCVD-grown, freestanding 1.5- $\mu \mathrm{m}$-thick $\operatorname{SiN}_{x}$ film to be $\sim 5 \mathrm{~W} \mathrm{~m}^{-1} \mathrm{~K}^{-1}$. Around the same time, Lee et al. [52] used a similar in-plane $3 \omega$ method to measure $\kappa_{\mathrm{r}}$ for a 550 -nm-thick, LPCVD-grown $\mathrm{SiN}_{x}$ film to be $5.4 \mathrm{~W} \mathrm{~m}^{-1} \mathrm{~K}^{-1}$, in agreement with the $3 \times$ thicker film measured by Jain and Goodson. Queen and Hellman [38] used a membrane-based nanocalorimeter approach to find that $\kappa_{\mathrm{r}}$ of 50 - and 200-nm-thick suspended $\mathrm{SiN}_{1.15}$ membranes were $\sim 2.5$ and $\sim 4.5 \mathrm{~W} \mathrm{~m}^{-1} \mathrm{~K}^{-1}$, respectively; the reduced value of the former was attributed to boundary scattering, possibly evidence for strong propagon contribution to $\kappa$. Alam et al. [42] used a MEMS-based experiment to measure the strain-dependent $\kappa_{\mathrm{r}}$ of a 50-nm-thick, LPCVD grown, stoichiometric $\mathrm{Si}_{1} \mathrm{~N}_{1-1.1}$ suspended film; the unstrained $\kappa_{\mathrm{r}}$ was $2.7 \mathrm{~W} \mathrm{~m}^{-1} \mathrm{~K}^{-1}$ but reduced to $0.34 \mathrm{~W} \mathrm{~m}^{-1} \mathrm{~K}^{-1}$ when tensile strain was increased to $2.4 \%$. In contrast, Ftouni et al. [39] used the reported stress-independent $\kappa_{\mathrm{r}}$ of 50- and 100nm-thick membranes to be $\sim 2.5-3 \mathrm{~W} \mathrm{~m}^{-1} \mathrm{~K}^{-1}$ for the four samples tested, with modest thickness dependence in thermal conductivity. Sikora et al. [43] used the $3 \omega$-Völklein method to measure $\kappa_{\mathrm{r}}$ of a LPCVD-grown, low-stress, 100-nm-thick $a-\mathrm{SiN}_{x}$ membrane to be $10 \mathrm{~W} \mathrm{~m}^{-1} \mathrm{~K}^{-1}$, in agreement with the seemingly outlier values determined by Zhang and Grigoropoulos. Bodenschatz et al. [44] measured $\kappa_{\mathrm{r}}$ of a 100-nm-thick $\mathrm{SiN}_{x}$ membrane to be $3 \mathrm{~W} \mathrm{~m}^{-1} \mathrm{~K}^{-1}$. Finally, Sultan et al. [35] used a MEMS-based micromachined suspended platform structure to measure $\kappa_{\mathrm{r}}$ for 500-nm-thick, LPCVD-grown $\operatorname{SiN}_{x}$ microbridges to be $\sim 2.5$ to $3.2 \mathrm{~W}$ $\mathrm{m}^{-1} \mathrm{~K}^{-1}$ at room temperature, a wider range but still in agreement with previous measurements from the same group [36]. These in-plane thermal conductivity data, along with additional pertinent properties, are tabulated in Table II in the Appendix. Taken as a whole, there is a wide variation in reported $\kappa_{\mathrm{r}}$ ranging from 1.2 to $13 \mathrm{~W} \mathrm{~m}^{-1} \mathrm{~K}^{-1}$ and no clear evidence of film thickness or deposition method systematically affecting $\kappa_{\mathrm{r}}$.

There have been fewer reports on the cross-plane thermal conductivity data of amorphous silicon nitride as compared to $\kappa_{r}$. Figure 1(b) plots these data as a function of film thickness. Lee and Cahill [50] first used the $3 \omega$ technique to measure the thickness dependence of $\kappa_{z}$ in PECVD grown $a-\mathrm{SiN}_{x}: \mathrm{H}$ (reported as $\mathrm{Si}_{1} \mathrm{~N}_{1.1}$ ) having thicknesses from 20 to $300 \mathrm{~nm}$ to reveal an increase in $\kappa_{\mathrm{z}}$ from $\sim 0.5$ to $\sim 0.8 \mathrm{~W} \mathrm{~m}^{-1} \mathrm{~K}^{-1}$ over this thickness range; however, they ascribe this trend to interfacial thermal resistance, as previously mentioned. However, a 180-nm sample grown with APCVD had a thermal conductivity of $\sim 1.5 \mathrm{~W} \mathrm{~m}^{-1} \mathrm{~K}^{-1}$, revealing that differences in deposition process can have much larger influences on thermal conductivity than film thickness. Govorkov et al. [53] used a differential photoacoustic method to measure $\kappa$ of sputterdeposited $\mathrm{Si}_{3} \mathrm{~N}_{4}$ to be $1.2 \mathrm{~W} \mathrm{~m}^{-1} \mathrm{~K}^{-1}$ for 100 -, 210-, and 420-nm films. Bai et al. [46] used transient thermoreflectance to measure $\kappa_{\mathrm{z}}$ of LPCVD-grown $\mathrm{Si}_{3} \mathrm{~N}_{4}$ films ranging in thickness from 37 to $200 \mathrm{~nm}$; they found an increasing $\kappa_{\mathrm{z}}$ with thickness, increasing from 1.24 to $2.09 \mathrm{~W} \mathrm{~m}^{-1} \mathrm{~K}^{-1}$. Coquil et al. [48] used the $3 \omega$ method to determine $\kappa_{\mathrm{z}}$ for a 500nm-thick, PECVD-grown $a$-SiN $x$ :H film (reported as $a$-SiN) to be $1.2 \pm 0.4 \mathrm{~W} \mathrm{~m}^{-1} \mathrm{~K}^{-1}$. Hopkins et al. [45] used TDTR to measure $\kappa_{\mathrm{z}}$ to be 3.1 and $3.5 \mathrm{~W} \mathrm{~m}^{-1} \mathrm{~K}^{-1}$ for a 46- and 
(a)

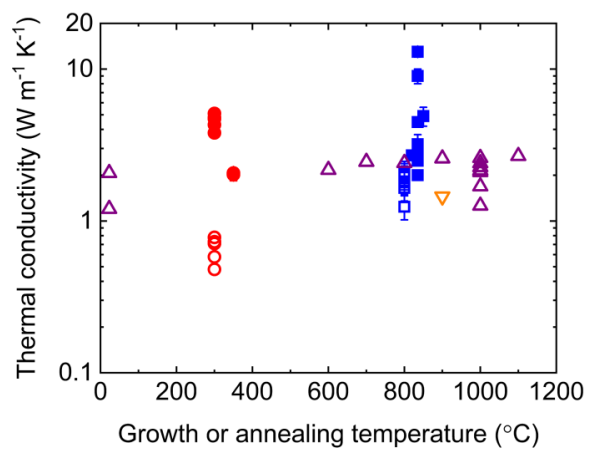

(b)

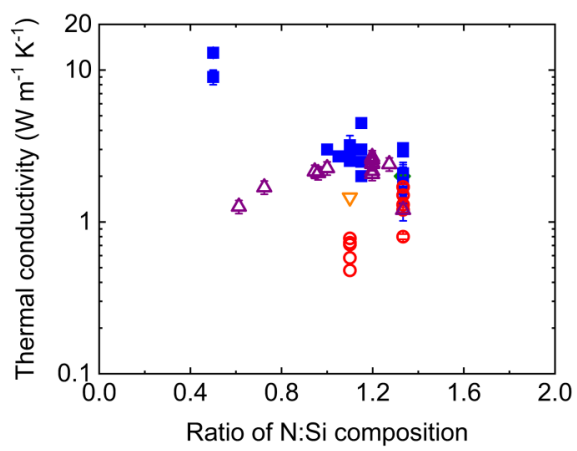

(c)

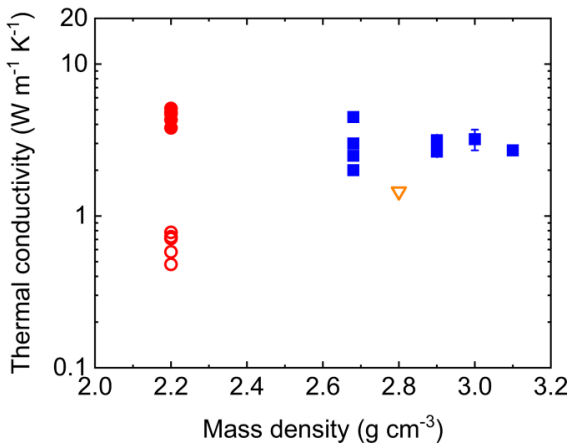

FIG. 2. Literature thermal conductivity vs. (a) temperature during growth (or post growth annealing temperature in the case of Marconnet et al. [54]), (b) Ratio of nitrogen to silicon composition in film, and (c) mass density. The available data points are tabulated in Tables II and III in the Appendix. Closed symbols represent $\kappa_{r}$ measurements and open symbols represent $\kappa_{z}$ measurements. The different deposition methods are indicated by different-shaped data points following the legend in Fig. 1: LPCVD $(\square)$, PECVD $(\bigcirc)$, APCVD $(\nabla)$, sputter $(\triangle)$. Outside of the work by Marconnet et al. [54] that demonstrated a change in thermal conductivity with a change in $\% \mathrm{~N}$ :\% Si composition, there are no clear trends in the thermal conductivity of amorphous silicon nitride films with growth (or annealing) temperature, ratio of N:Si composition, or mass density.

232-nm-thick sample, respectively. Finally, Bogner et al. [49] used a differential $3 \omega$ method to determine that $\kappa_{\mathrm{z}}$ of $a-\mathrm{SiN}_{x}: \mathrm{H}$ (reported as $a-\mathrm{Si}_{3} \mathrm{~N}_{4}$ ) increased from 0.8 to $1.7 \mathrm{~W} \mathrm{~m}^{-1} \mathrm{~K}^{-1}$ when film thickness increased from 298 to $1001 \mathrm{~nm}$. For $\kappa_{z}$, the individual studies revealing a thickness dependence in $\kappa_{z}$ could make a stronger case for size effects; however, as previously mentioned in this section, these trends could most likely be ascribed to thermal boundary resistances obfuscating the measurements of the effective thermal conductivity of the thin films. Thus, like the case for $\kappa_{\mathrm{r}}$, when taken as a whole, there is no obvious trend in thickness dependence in $\kappa_{z}$, particularly when compared with the evidence provided for amorphous $\mathrm{Si}$ [23], thus raising further questions regarding propagon versus diffuson transport contributions in $a-\mathrm{SiN}_{x}: \mathrm{H}$. Furthermore, we must consider the fact that the reported stoichiometries of the silicon nitride films also vary among the different studies. To this point, Marconnet et al. [54] studied this effect by using TDTR to measure the thermal conductivity of 400-nm-thick sputtered $a-\mathrm{SiN}_{x}$ films with $\% \mathrm{~N}: \% \mathrm{Si}$ ratios ranging from 0.6 to 1.2 . Based on $\% \mathrm{~N}: \% \mathrm{Si}$ ratio and annealing temperature, $\kappa_{z}$ could vary by a factor of 2 . However, the density, hydrogen content and atomic structure of their films were not characterized, and thus the underlying mechanisms as to why $\kappa_{z}$ increases with annealing in their films is not entirely clear. These cross-plane thermal conductivity data, along with additional pertinent properties, are tabulated in Table III in the Appendix.

The work by Marconnet et al. [54] suggests the possibility that the deposition conditions could be changing the atomic scale properties of the amorphous silicon nitride films reported in Figs. 1(a) and 1(b) and thus leading to the variability in thermal conductivity values. To study this effect, we plot the thermal conductivities of the various amorphous silicon nitride films as a function of growth (or annealing) temperature, $\% \mathrm{~N}: \%$ Si ratio, and mass density in Figs. 2(a), 2(b) and 2(c), respectively. We note that these properties are not reported for all films, and thus we only plot those data in which these properties are available (refer to Tables II and III for available values). In these figures, the in-plane values are shown as filled symbols while the cross-plane values are shown as open symbols, with the legend for deposition method following that in Figs. 1(a) and 1(b). Outside of the work by Marconnet et al. [54] that demonstrated a change in thermal conductivity with a change in $\% \mathrm{~N}: \% \mathrm{Si}$ composition, there are no clear trends in the thermal conductivity of amorphous silicon nitride films with growth (or annealing) temperature, ratio of $\mathrm{N}: \mathrm{Si}$ composition, or mass density.

Clearly, since complete chemical and structural characterization is lacking for all previously studied films, the current understanding of what drives and influences the vibrational thermal conductivity in amorphous silicon nitride films is lacking. Furthermore, we note that the presence of hydrogen in all of these aforementioned films has not been considered, but at least in some of these films, hydrogen is most certainly present, which would not only impact the reported $\% \mathrm{~N}: \% \mathrm{Si}$ composition, but also could change the vibrational transport properties, as hydrogen has been shown to have strong effects on the thermal conductivity of amorphous silicon, amorphous silicon oxide, and amorphous silicon carbide thin films in previous works $[30,64,65]$. This warrants the necessity of our work described in the remainder of this manuscript in which we report on the measured thermal conductivity of a series of PECVD $a-\mathrm{SiN}_{x}: \mathrm{H}$ thin films of varying thicknesses with control over the hydrogen composition and resulting full characterization of chemical composition, bonding, and average atomic distances.

\section{EXPERIMENTAL METHODS AND MEASUREMENTS}

\section{A. Film deposition}

The samples measured in this study include seven sets of $a-\mathrm{SiN}_{x}: \mathrm{H}$ samples having varying stoichiometries. Each set is comprised of six samples varying in thickness from nominally $50 \mathrm{~nm}$ up to $2 \mu \mathrm{m}$. In addition, we studied two sets of $a-\mathrm{Si}: \mathrm{H}$ samples varying in thickness from nominally $50 \mathrm{~nm}$ up to 2 $\mu \mathrm{m}$ and two sets of stoichiometric $\mathrm{Si}_{3} \mathrm{~N}_{4}$ films. The $\mathrm{Si}_{3} \mathrm{~N}_{4}$ 
films include four samples grown via LPCVD and having film thicknesses ranging from nominally 50 to $500 \mathrm{~nm}$ and an additional sample grown via high-temperature CVD (HTCVD) [66]. All samples were grown on (100) Si substrates. Both $a-\mathrm{SiN}_{x}: \mathrm{H}$ and $a$-Si:H sample sets were grown via PECVD using the same base recipe and flowing $\mathrm{NH}_{3}$ to achieve the $a-\mathrm{SiN}_{x}: \mathrm{H}$ composition. The $a-\mathrm{Si}: \mathrm{H}$ samples were grown with an intermediate $49 \mathrm{~nm} a-\mathrm{SiO}_{2}$ layer between the film and substrate; this $a-\mathrm{SiO}_{2}$ layer is necessary as $a$-Si:H alone does not adhere to the $\mathrm{Si}$ substrate. To systematically control the ratio of at. $\% \mathrm{~N}$ to at. $\% \mathrm{Si}$ within the $a-\mathrm{SiN}_{x}: \mathrm{H}$ samples, the $\mathrm{NH}_{3}$ flow rate was varied during growth from 1500 to 18000 sccm, while the $\mathrm{SiH}_{4}$ flow rate was held constant at 600 sccm. To explore the role of hydrogen in $a-\mathrm{SiN}_{x}: \mathrm{H}$ thermal properties, the 1500, 9000, and $18000 \mathrm{sccm} \mathrm{NH}_{3}$ samples were additionally annealed at $650,775,900$, and $1000{ }^{\circ} \mathrm{C}$ in an Argon filled tube furnace for $4 \mathrm{~h}$.

\section{B. Composition and density}

The compositions and densities were characterized using a combined nuclear reaction analysis and Rutherford backscattering (NRA-RBS) measurement performed at the University of Albany Dynamitron Accelerator Laboratory [67], while Fourier-transform infrared spectroscopy (FTIR) was used as an auxiliary technique to complement composition characterization and quantify bond states. The composition determined by the NRA-RBS was used to determine the average atomic coordination of the films $(\langle r\rangle)$, which is representative of the number of degrees of freedom and bond constraints for each atom. The average coordination (or connectivity) for the $a$ $\mathrm{SiN}_{x}: \mathrm{H}$ films was calculated according to the expression

$$
\langle r\rangle=\frac{4[S i]+3[N]+[H]}{[S i]+[N]+[H]},
$$

where $[S i],[N]$, and $[H]$ signify the atomic concentration of silicon, nitrogen and hydrogen in the $a-\mathrm{SiN}_{x}: \mathrm{H}$, respectively. The uncertainty in this approach to determining $\langle r\rangle$ is approximately $\pm 5 \%$ [68]. Film thicknesses for the $a-\mathrm{SiN}_{x}: \mathrm{H}$ and $a$-Si:H samples were characterized by ultraviolet-visible (UVVIS) spectroscopic ellipsometry using an absorbing model [69]. Additionally, the as-deposited film thicknesses were corroborated by fitting the undulations in the background for the transmission FTIR spectra [70]. The thicknesses for the annealed samples were determined via UV-VIS spectroscopic ellipsometry and corroborated based on the infrared spectra collected using infrared variable angle spectroscopic ellipsometry (IR-VASE). X-ray reflectivity (XRR) was also used to corroborate the densities measured via RBS [68]. Compositions and densities of the as-deposited films are tabulated in Table IV in the Appendix.

\section{Porosity: Positronium annihilation lifetime spectroscopy}

The relative porosities and pore sizes of the $a-\mathrm{SiN}_{x}: \mathrm{H}$ films were examined with positronium annihilation lifetime spectroscopy (PALS) using an electrostatically focused beam of positrons. Details of such beam-PALS measurements have been previously described elsewhere [71,72]. A review of PALS measurements and their characterization of amorphous materials can be found in Ref. [72]. Briefly, PALS spectra with $\sim 10^{7}$ events were acquired at room temperature with a channel plate start-fast plastic scintillator stop lifetime system with a time resolution of $500 \mathrm{ps}$. A positron beam implantation energy of $3.2 \mathrm{keV}$ was utilized where the mean implantation depth is around $100 \mathrm{~nm}$ and no positrons should penetrate into the Si substrate. Each PALS spectrum required four lifetimes (and corresponding intensity (signal strength)) for adequate fitting — a short $\sim 0.4 \mathrm{~ns}$ positron lifetime, a single (average) $\sim 2$ ns positronium (Ps) lifetime in the film (the relevant PALS signal), and two longer Ps lifetimes ( $\sim 7 \mathrm{~ns}$ and $\sim 100 \mathrm{~ns})$ that are ever-present in beam PALS and are related to positrons that backscatter from the beam and form Ps in vacuum at the sample surface and hence carry no information about the film porosity. The fitted average positronium lifetime is related to the average pore diameter, assuming a spherical pore model which allows the specific hole volume, $V_{\text {hole }}$, to be calculated. The corresponding fitted Ps signal intensity, $I$, is considered to be proportional to the number density of isolated voids/holes and hence the average film porosity is proportional to the product, $I V_{\text {hole }}$.

\section{Thermal conductivity and heat capacity}

The cross-plane thermal conductivities were measured using TDTR after depositing an $80 \mathrm{~nm} \mathrm{Al} \mathrm{film} \mathrm{onto} \mathrm{the} \mathrm{samples}$ to serve as a transducer of optical energy to thermal energy; henceforth, all data presented and discussed will be indicative of the measured cross-plane thermal conductivities of the various amorphous silicon nitride films, and referred to only as thermal conductivity. In the TDTR measurements of thermal conductivity of the various $a-\mathrm{SiN}_{x}: \mathrm{H}$ samples, pump and probe $1 / e^{2}$ diameters were 36 and $17 \mu \mathrm{m}$, respectively, and the pump modulation frequency was $8.4 \mathrm{MHz}$; these two conditions ensure measurement sensitivity is limited to $\kappa_{\mathrm{z}}$ rather than $\kappa_{\mathrm{r}}$. To avoid estimation of heat capacity, which could potentially vary based on density and stoichiometry, a combined TDTR and FDTR method was used, as discussed in several previous works [73-77], to simultaneously measure the thermal conductivity and volumetric heat capacity of selected $\sim 200$-nm-thin film samples in each set of the annealed $a$-SiN:H samples listed in Table I. For these selected films, we use multiple modulation frequencies to decouple thermal conductivity from volumetric heat capacity, thereby measuring both quantities [73-76]. In this case, the modulation frequencies used were 8.4, 4.8, and 1.3 MHz. Using this approach, the heat capacity is determined to range from $\sim 1.76$ to $2 \mathrm{MJ} \mathrm{m}^{-3} \mathrm{~K}^{-1}$ for all $a$-SiN $x$ :H samples, in agreement with Chen et al.'s measurement of $a-\mathrm{SiN}_{x}: \mathrm{H}(19.3$ at.\% H). The measured heat capacities for the selected samples measured are tabulated in Table I. As a further check, this procedure was performed on all LPCVD-grown $\mathrm{Si}_{3} \mathrm{~N}_{4}$ samples; the measured heat capacities fell within $2.0 \pm 0.2 \mathrm{~J} \mathrm{~cm}^{-3} \mathrm{~K}^{-1}$, which equates to $0.71 \pm 0.07 \mathrm{~J} \mathrm{~g}^{-1} \mathrm{~K}^{-1}$, in agreement with prior studies on $a-\mathrm{SiN}_{x}[33,38,39,42]$.

\section{E. Average atomic pair distances: Selected-area electron diffraction}

To complement the detailed chemical and physical analysis, the as-deposited $(500 \mathrm{~nm})$ and $1000{ }^{\circ} \mathrm{C}$ annealed $(200$ 
TABLE I. Properties of annealed $a-\mathrm{SiN}_{x}: \mathrm{H}$ samples. RBS was used to measure at. $\% \mathrm{~N}$, at.\% $\mathrm{Si}$, at.\% $\mathrm{H}$, coordination number $(\langle r\rangle)$, and density $(\rho)$. From this we calculate the ratio of at. $\% \mathrm{~N}$ to at. $\% \mathrm{Si}(\% \mathrm{~N}: \% \mathrm{Si})$. XRR was used to corroborate the densities measured with RBS [68]. Thickness $(d)$ was determined with IR-VASE. Thermal conductivity was measured via TDTR.

\begin{tabular}{|c|c|c|c|c|c|c|c|c|c|}
\hline Anneal Temperature $\left({ }^{\circ} \mathrm{C}\right)$ & $\% \mathrm{~N}$ & $\% \mathrm{Si}$ & $\% \mathrm{~N}: \% \mathrm{Si}$ & $\% \mathrm{H}$ & $\langle r\rangle$ & $d(\mathrm{~nm})$ & $\rho\left(\mathrm{g} \mathrm{cm}^{-3}\right)$ & $\kappa\left(\mathrm{W} \mathrm{m}^{-1} \mathrm{~K}^{-1}\right)$ & $C\left(\mathrm{~J} \mathrm{~cm}^{-3} \mathrm{~K}^{-1}\right)$ \\
\hline \multicolumn{10}{|l|}{1500 sccm $\mathrm{NH}_{3}$ series } \\
\hline as deposited $\left(400^{\circ} \mathrm{C}\right)$ & 28.5 & 51.4 & 0.55 & 20.1 & 3.11 & 194 & $2.3 \pm 0.10$ & $0.89 \pm 0.09$ & $1.76 \pm 0.3$ \\
\hline 650 & 30.2 & 67.6 & 0.45 & 2.2 & 3.63 & 171 & $2.8 \pm 0.15$ & $1.46 \pm 0.16$ & $1.92 \pm 0.3$ \\
\hline 775 & 33.2 & 66.6 & 0.50 & 0.2 & 3.66 & 161 & $2.9 \pm 0.15$ & $1.88 \pm 0.22$ & $1.77 \pm 0.3$ \\
\hline 900 & 32.7 & 67.1 & 0.49 & 0.2 & 3.67 & 158 & $3.1 \pm 0.15$ & $1.90 \pm 0.22$ & $1.85 \pm 0.3$ \\
\hline 1000 & 34.0 & 66.0 & 0.52 & 0.0 & 3.66 & 147 & $3.3 \pm 0.15$ & $2.63 \pm 0.39$ & $1.86 \pm 0.3$ \\
\hline \multicolumn{10}{|l|}{$9000 \mathrm{sccm} \mathrm{NH}_{3}$ series } \\
\hline as deposited $\left(400^{\circ} \mathrm{C}\right)$ & 37.7 & 36.4 & 1.03 & 26.0 & 2.84 & 171 & $2.3 \pm 0.10$ & $0.91 \pm 0.08$ & $1.87 \pm 0.3$ \\
\hline 650 & 44.4 & 45.8 & 0.97 & 9.8 & 3.26 & 168 & $2.5 \pm 0.15$ & $1.41 \pm 0.12$ & $1.92 \pm 0.3$ \\
\hline 775 & 49.5 & 44.3 & 1.11 & 6.2 & 3.32 & 144 & $2.8 \pm 0.15$ & $1.41 \pm 0.15$ & \\
\hline 900 & 50.4 & 48.4 & 1.04 & 1.2 & 3.46 & 132 & $3.1 \pm 0.15$ & $1.58 \pm 0.18$ & \\
\hline 1000 & 48.8 & 51.2 & 0.95 & 0.0 & 3.51 & 131 & $3.1 \pm 0.15$ & $2.25 \pm 0.29$ & $1.93 \pm 0.3$ \\
\hline \multicolumn{10}{|l|}{$18000 \mathrm{sccm} \mathrm{NH} \mathrm{NH}_{3}$ series } \\
\hline as deposited $\left(400^{\circ} \mathrm{C}\right)$ & 43.4 & 30.8 & 1.41 & 25.8 & 2.79 & 176 & $2.3 \pm 0.10$ & $1.14 \pm 0.08$ & \\
\hline 650 & 52.3 & 38.2 & 1.37 & 9.6 & 3.19 & 157 & $2.8 \pm 0.15$ & $1.42 \pm 0.12$ & $1.93 \pm 0.3$ \\
\hline 775 & 50.2 & 42.1 & 1.19 & 7.7 & 3.27 & 142 & $2.9 \pm 0.15$ & $1.50 \pm 0.14$ & \\
\hline 900 & 54.8 & 42.5 & 1.29 & 2.7 & 3.37 & 137 & $2.9 \pm 0.15$ & $1.88 \pm 0.19$ & \\
\hline 1000 & 55.0 & 45.0 & 1.22 & 0.0 & 3.45 & 143 & $2.8 \pm 0.15$ & $2.13 \pm 0.24$ & $1.82 \pm 0.3$ \\
\hline
\end{tabular}

and $500 \mathrm{~nm}) 18000 \mathrm{sccm} \mathrm{NH}_{3} a-\mathrm{SiN}_{x}: \mathrm{H}$ films and $500 \mathrm{~nm}$ HTCVD $a-\mathrm{Si}_{3} \mathrm{~N}_{4}$ film were chosen for selected-area electron diffraction (SAED) measurements at $300 \mathrm{dV}$ to determine the distribution of average atomic pair distances using a FEI Titan transmission electron microscope (TEM). These samples were selected for SAED-TEM analysis to study the role that annealing of the samples and subsequent change in hydrogen composition has on the average atomic pair distances as compared to a HTCVD stoichiometric $a-\mathrm{Si}_{3} \mathrm{~N}_{4}$ film. An example diffraction pattern is shown in Fig. 3(a) where broad radially symmetric amorphous rings from the amorphous thin film and sharp high intensity Bragg reflections from the aluminum transducer are seen. The diffraction pattern center was calibrated, then the diffraction patterns were radially integrated excluding the beam stop, as indicated by red annotations in Fig. 3(a), providing a radially integrated diffraction pattern (RIDP) as shown in Fig. 3(b). Forming the RIDP allows for the broad peaks formed by the amorphous peaks to be fitted. Sharply peaked Bragg reflections from the Al capping layer were used to calibrate the wave vector, $q$, of the RIDP to ensure measurement accuracy, then were removed by interpolation to remove possible skewing of fitted amorphous peaks. Each RIDP was fitted with a power law background and six Gaussian functions, as shown in Fig. 3(c). The average atomic pair distances, $R_{\mathrm{AAP}}$, can be determined from $q$ via

$$
R_{\mathrm{AAP}, i}=\frac{1}{q_{i}},
$$

(a)

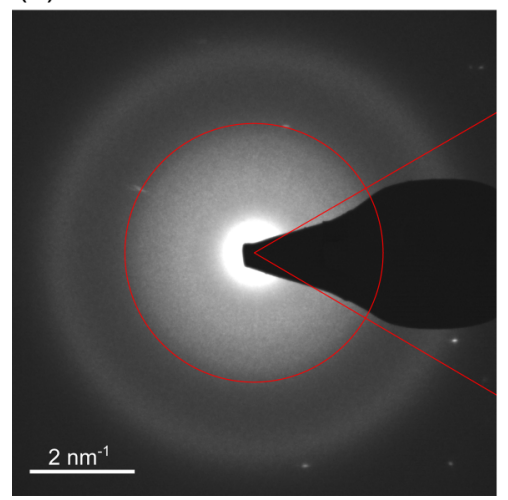

(b)

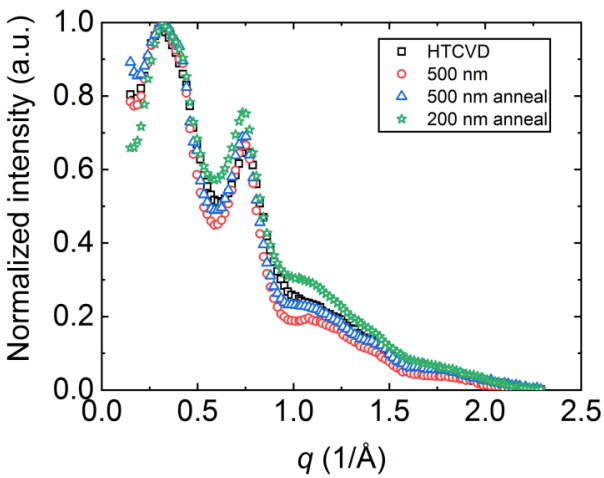

(c)

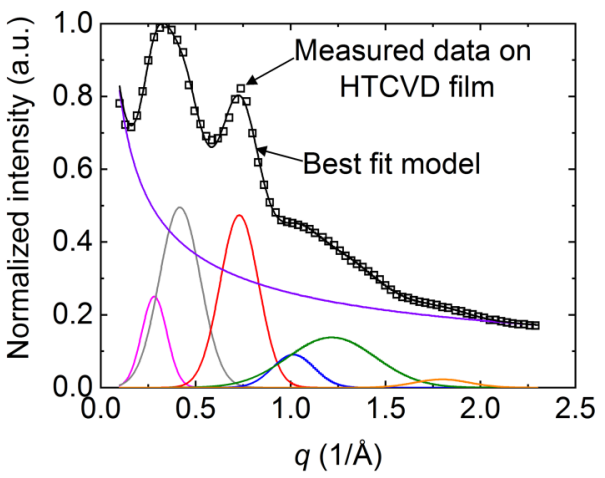

FIG. 3. (a) Selected area electron diffraction pattern showing diffuse rings from the $a$-SiN $x: \mathrm{H}$ thin film and sharply peaked Bragg reflections from the Al transducer. (b) Raw RIDP from the 500-nm-thick HTCVD $a$-Si ${ }_{3} \mathrm{~N}_{4}$ film, the 500-nm-thick as-deposited 18000 sccm $a$-SiN $x$ : $\mathrm{H}$ film, the 500 -nm-thick $18000 \mathrm{sccm} a$-SiN $x: \mathrm{H}$ film annealed at $1000^{\circ} \mathrm{C}$, and the 200 -nm-thick $18000 \operatorname{sccm} a-\mathrm{SiN}_{x}: \mathrm{H}_{\text {film }}$ annealed at $1000{ }^{\circ} \mathrm{C}$. Only every 30th data point for each exemplary data set are shown for clarity. (c) Example fit to a RIDP on the HTCVD film. Each RIDP was fitted with a power law background and six Gaussian functions, which for this fit are shown here along with the resulting best fit model. Only every 25th data point from the measured data set on the HTCVD film presented here is shown for clarity. 
and the distributions about the average atomic pair distances, $\Delta R_{\mathrm{AAP}}$, via

$$
\Delta R_{\mathrm{AAP}, i}=\frac{1}{q_{i}-\frac{\Delta q_{i}}{2}}-\frac{1}{q_{i}+\frac{\Delta q_{i}}{2}},
$$

where the index $i$ denotes a specific peak and $\Delta q$ represents the peak full-width at half-maximum. The average atomic pair distances can be directly and quantitatively extracted from the diffraction patterns by converting the peak centers $q_{i}$ to $R_{\mathrm{AAP}, i}$ with Eq. (2). Converting peak full-width at half-maximum of a specific peak $\left(\Delta q_{i}\right)$ to distributions about those average atomic pair distances $\left(\Delta R_{n n, i}\right)$ requires more care. The measured widths of peaks in the RIDP are a combination of: (1) convergence angle, (2) diffuse scattering from low-energy inelastic scattering and thermal diffuse scattering, and (3) the natural distribution of distances found in the sample. Without zero-loss filtering and deconvolution, (1) and (2) cannot be removed from the diffraction data preventing direct quantitative comparisons. However, if the thickness of compared samples and acquisition conditions are approximately the same, then the contribution from (1) and (2) are the same in each sample allowing for a qualitative comparison of the distribution around an average atomic pair distance.

Figure 3(b) shows Bragg peak-subtracted RIPD generated from the selected-area electron diffraction acquired from the 500-nm-thick HTCVD $a-\mathrm{Si}_{3} \mathrm{~N}_{4}$ film, the 500-nm-thick as-deposited $18000 \mathrm{sccm} a-\mathrm{SiN}_{x}: \mathrm{H}$ film, the 500-nm-thick $18000 \mathrm{sccm} a-\mathrm{SiN}_{x}: \mathrm{H}$ film annealed at $1000^{\circ} \mathrm{C}$, and the $200-$ nm-thick $18000 \mathrm{sccm} a$-SiN $x: \mathrm{H}$ film annealed at $1000^{\circ} \mathrm{C}$. The sharp $0.721 / \AA$ peak is related to the Si-N first average atomic pair distance [78-80]. The first two peaks in the RIDP have wave vectors of around 0.29 and $0.411 / \AA$, which translates to the first Si-Si and N-N distances, respectively [78-80].

\section{F. Summary of experimentally measured properties}

The composition and thermal, chemical, optical, and mechanical properties of the as-deposited 200-nm-thick PECVD $a$-Si:H and $\mathrm{SiN}_{x}: \mathrm{H}$ films and 500-nm-thick LPCVD and HTCVD $a-\mathrm{Si}_{3} \mathrm{~N}_{4}$ films are tabulated in Table IV in the Appendix, including: $\mathrm{NH}_{3}$ flow rate during deposition, target thickness and thickness measured via spectroscopic ellipsometry, NRA-RBS elemental composition and mass density, calculated coordination number $\langle r\rangle$, film stress as determined by wafer bow and Stoney's formula as described in Ref. [68], nanoindentation modulus and hardness as described in Refs. [55] and [68], PALS average pore diameter and relative porosity, and TDTR thermal conductivity. The composition and thermal conductivity for the 200-nm-thick annealed $a-\mathrm{SiN}_{x}: \mathrm{H}$ films are reported in Table $\mathrm{I}$ of the manuscript. These properties are reported at 200- and 500-nm thickness due to the ability to perform all of these material characterizations on the same sample and limitations in performing some measurements on thinner or thicker films. While NRA, RBS, PALS, and nanoindentation measurements were not performed for every sample in this study, the results from the 200- to 500-nm-thick films are expected to be representative for films deposited at different thicknesses under identical conditions.

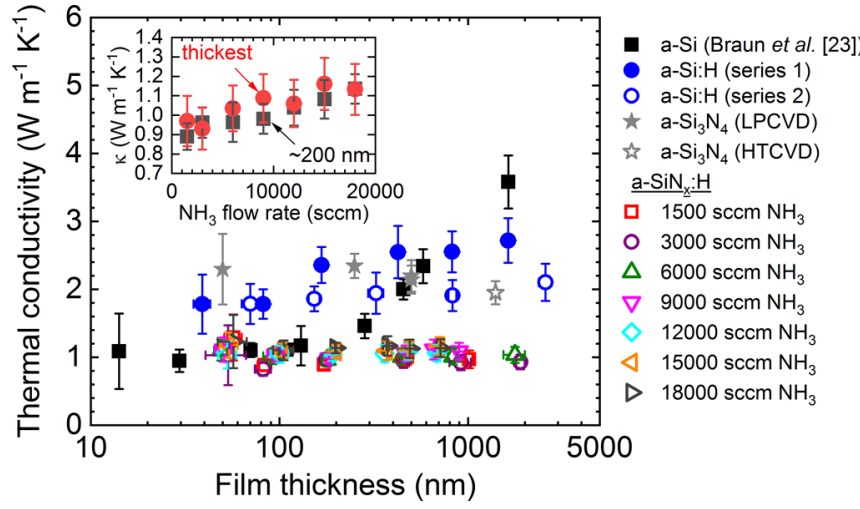

FIG. 4. Measured thermal conductivity $(\kappa)$ vs. film thickness for all samples under study: two sets of $a$-Si:H samples, seven sets of $a$-SiN:H samples grown with varying $\mathrm{NH}_{3}$ flow rates $(1500,3000$, 6000, 9000, 12000, 15000 , and $18000 \mathrm{sccm}$ ), and CVD-grown $\mathrm{Si}_{3} \mathrm{~N}_{4}$ samples. For comparison, also included are the results for $a-\mathrm{Si}$ from our previous work [23]. (Inset) Thermal conductivity vs. $\mathrm{NH}_{3}$ flow rate for the $\sim 200 \mathrm{~nm}$ sample and thickest $(\sim 1-2 \mu \mathrm{m})$ sample of each set.

\section{RESULTS AND DISCUSSION}

\section{A. Thermal conductivity dependencies on thickness, processing conditions, and porosity}

Figure 4 shows the measured thermal conductivity as a function of film thickness for all as-deposited samples; included for comparison are the measured thermal conductivities of various $a$-Si thin films as a function of thickness from our previous work [23]. Beginning with the stoichiometric $a-\mathrm{Si}_{3} \mathrm{~N}_{4}$ samples, the measured $\kappa$ for a 50-, 250-, and two 500-nm films grown via LPCVD were equivalent at $\sim 2.1-2.3 \mathrm{~W} \mathrm{~m}^{-1} \mathrm{~K}^{-1}$ with no clear thickness dependence within uncertainty. A mean value of $\kappa$ of $1.95 \mathrm{~W} \mathrm{~m}^{-1} \mathrm{~K}^{-1}$ was measured for the HTCVD-grown $\mathrm{Si}_{3} \mathrm{~N}_{4}$, which is only slightly lower and within uncertainty of the thicker LPCVD films. Next, for the $a$-SiN $x$ :H samples, we observe that all sets possess a thickness-independent thermal conductivity of $\sim 1 \mathrm{~W} \mathrm{~m}^{-1} \mathrm{~K}^{-1}$. There is a minor dependence of thermal conductivity with $\mathrm{NH}_{3}$ flow rate, showing that samples fabricated with higher $\mathrm{NH}_{3}$ flow rates generally possess higher thermal conductivities by as much as $25 \%$. This is shown in the inset to Fig. 4, where the thermal conductivity relation with $\mathrm{NH}_{3}$ flow rate is plotted for the $200 \mathrm{~nm}$ and thickest samples (nominally $1-2 \mu \mathrm{m})$ for each set.

Regardless of the thickness, in general, $\kappa$ increases modestly with an increase in $\mathrm{NH}_{3}$ flow rate during film deposition (cf. Fig. 4, inset). Additionally, for each individual series, there is no observable increase in $\kappa$ with increasing film thickness. This finding is in contrast to the $a$-Si:H series 1 sample set, which shows an increasing $\kappa$ with increasing film thickness. The size effects observed for the $a$-Si:H series 1 samples are less pronounced than the $a$-Si samples from Braun et al. [23], suggesting that the addition of hydrogen is restricting the propagon thermal transport to some extent. This is further supported by the lack of thickness dependence in our $a$-Si:H series 2 sample set, which contains more hydrogen than the series 1 sample set $(7.1$ at. $\% \mathrm{H}$ for the measured 


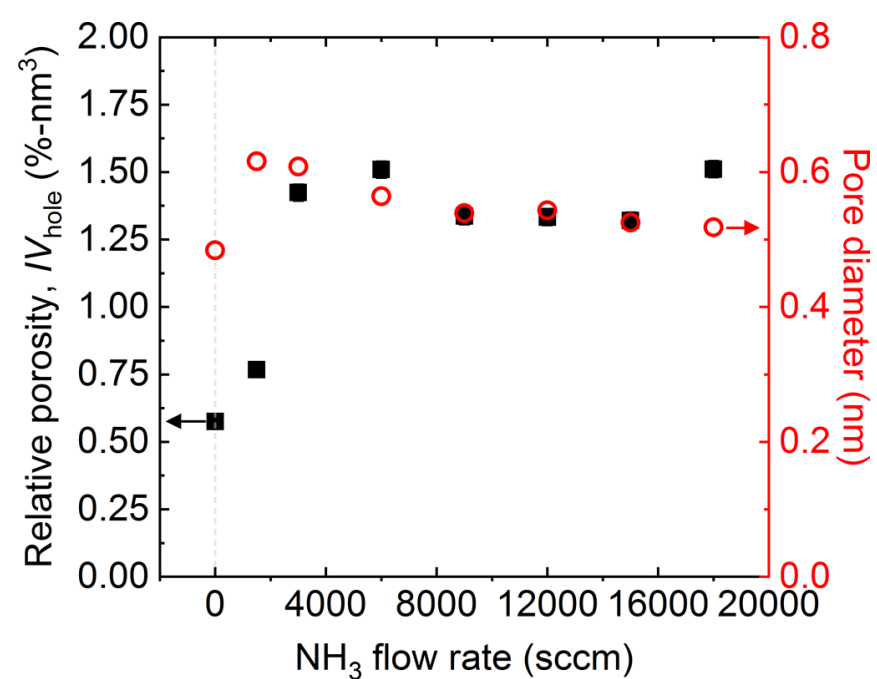

FIG. 5. Positronium annihilation lifetime spectroscopy (PALS) relative porosity $\left(\mathrm{IV}_{\text {hole }}\right)$ and spherical pore diameter for PECVD $a-\mathrm{SiN}_{x}: \mathrm{H}$ versus ammonia $\left(\mathrm{NH}_{3}\right)$ gas flow rate.

sample in series 1 and $12.5 \%$ for the measured sample in series 2-see Table IV in the Appendix). This idea is in conceptual agreement with the findings of Liu et al. [64], who note that for an $80 \mu \mathrm{m}$ thick $a$-Si:H sample having 1 at.\% $\mathrm{H}$ has a thermal conductivity of $4.5 \mathrm{~W} \mathrm{~m}^{-1} \mathrm{~K}^{-1}$, with decreases in $a$-Si:H thermal conductivity arising from reductions in some combination of sample thickness and hydrogen composition; our results align with Liu et al.'s [64] findings and extend this conceptual agreement to much thinner film thicknesses. The $a$-Si:H results indicate that, while hydrogen can affect the ability of propagons to contribute to thermal conductivity, it may not eliminate propagon contributions to thermal conductivity completely, which we posit due to the magnitude of the thermal conductivity of the $a$-Si:H series 1 are compared to the thermal conductivity of the thin film $a-\mathrm{Si}$ samples reported on by Braun et al. [23].

An additional structural defect that could be influencing the thermal conductivity of the $a-\mathrm{SiN}_{x}: \mathrm{H}$ films in this work is porosity. PALS analysis of the as-deposited 200-nm-thick $a-\mathrm{SiN}_{x}: \mathrm{H}$ films shows evidence of noninterconnected porosity in all films. As shown in Fig. 5, the $I V_{\text {hole }}$ product, which is a measure of relative porosity, increased initially with increasing $\mathrm{NH}_{3}$ flow rate but saturated at approximately 6000 sccm $\mathrm{NH}_{3}$. The increased porosity with $\mathrm{NH}_{3}$ flow rate runs somewhat counter to the observed increase in mass density also observed to occur with increasing $\mathrm{NH}_{3}$ flow rate (cf. Table IV in the Appendix). However, the increased porosity does correlate with the increased hydrogen content observed in the $a-\mathrm{SiN}_{x}: \mathrm{H}$ films with increasing $\mathrm{NH}_{3}$ flow rate.

Figure 5 also shows the fitted average spherical pore diameter as a function of $\mathrm{NH}_{3}$ flow rate. The pore diameter increases from $0.48 \mathrm{~nm}$ for pure $a-\mathrm{Si}: \mathrm{H}$ to $0.62 \mathrm{~nm}$ for $1500 \mathrm{sccm} \mathrm{NH} \mathrm{N}_{3}$, and then slowly decreases to $0.52 \mathrm{~nm}$ at the highest $\mathrm{NH}_{3}$ flow rate of $18000 \mathrm{sccm}$. These results are consistent with prior PALS measurement of porosity in PECVD $a-\mathrm{SiN}_{x}: \mathrm{H}$ by Uedono et al. [81] where pore diameters of $0.36-0.49 \mathrm{~nm}$ were determined for films with densities of $2.1-2.6 \mathrm{~g} \mathrm{~cm}^{-3}, \% \mathrm{~N}$ :\% Si ratios of $1.33-1.47$, and

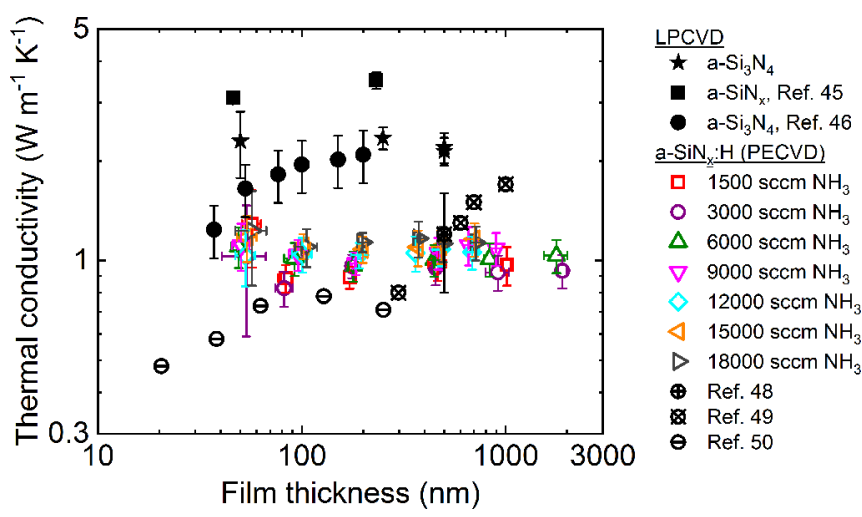

FIG. 6. Thermal conductivity vs. film thickness for $a-\mathrm{SiN}_{x}: \mathrm{H}$ samples measured in this study, compared with $a-\mathrm{SiN}_{x}$ samples reported in the literature. Samples in Refs. [45] and [46] were grown via LPCVD while those in Refs. [48-50] were grown via PECVD.

hydrogen content from $4.8-13.2$ at.\%. Since the $a-\mathrm{SiN}_{x}: \mathrm{H}$ thermal conductivity does not appear to decrease with the increased porosity produced by the increasing $\mathrm{NH}_{3}$ flow rate, these results suggest that pores on the order of $0.4-0.6 \mathrm{~nm}$ in size are not sufficiently large to act as scattering sites for propagons or diffusons in $a-\mathrm{SiN}_{x}: \mathrm{H}$. However, we cannot rule out the possibility that the porosity, which will change the density, could be impacting the thermal conductivity of the $a-\mathrm{SiN}_{x}: \mathrm{H}$ via other mechanisms (e.g., changing the heat capacity or mode diffusivity). The relatively constant porosity in our as-deposited $a$-SiN $x: \mathrm{H}$ films prevents us from studying this in more detail, but through high temperature annealing, we shed more insight into this possibility, which we discuss in further detail later in this subsection.

It is instructive at this point to now compare the thermal conductivities of our unannealed PECVD-grown $a$-SiN ${ }_{x}: \mathrm{H}$ and LPCVD-grown $a$-Si $\mathrm{Si}_{3}$ films to the prior reports on the cross-plane thermal conductivities of amorphous silicon nitride films grown by similar techniques shown in Fig. 1(b) and discussed in Sec. II. We plot these cross-plane thermal conductivity data together as a function of film thickness in Fig. 6. Our LPCVD-grown films reported in this work show relatively good agreement with the prior reports by Bai et al. [46] and Hopkins et al. [45]. Given that the densities of the films in these prior works were not reported, and in the case of Hopkins et al. [45] the stoichiometry was not reported, we cannot preclude the fact that changes in these film properties could lead to the relatively small differences in the measured thermal conductivities.

We observe more pronounced disagreement among our reported values and those in the literature for the PECVD-grown films. One obvious possible source of this discrepancy is differing stoichiometries (including hydrogen compositions), but we can only speculate on this since the hydrogen compositions of these PECVD-grown films from previous works were not reported. Another possibility, as discussed earlier in Section II, is that thermal boundary resistances were impacting the measured thermal conductivities of the PECVD-grown films reported in Refs. [48-50], as was explicitly discussed by Lee et al. [50]. TDTR measurements have the advantage of being able to separate thermal boundary resistances from 
(a)

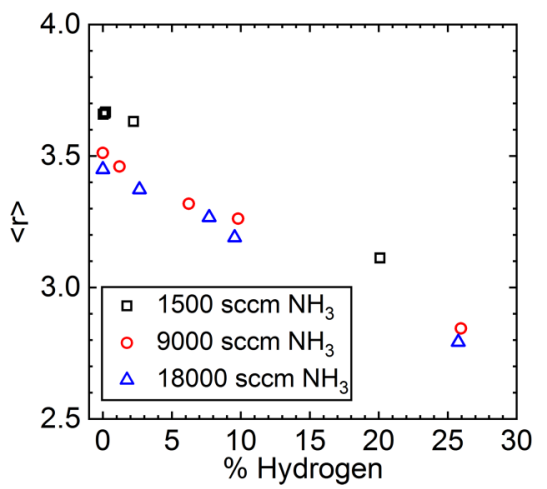

(b)

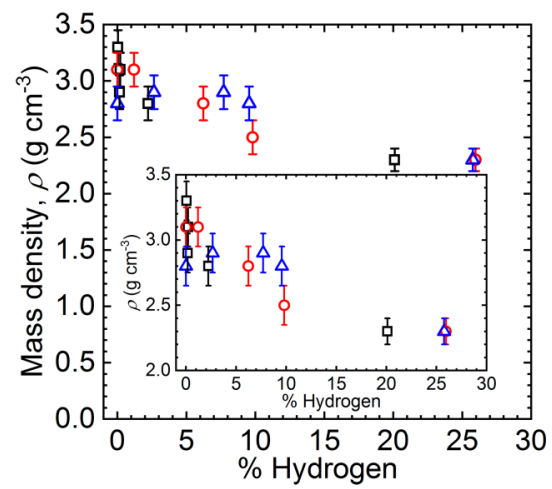

(c)

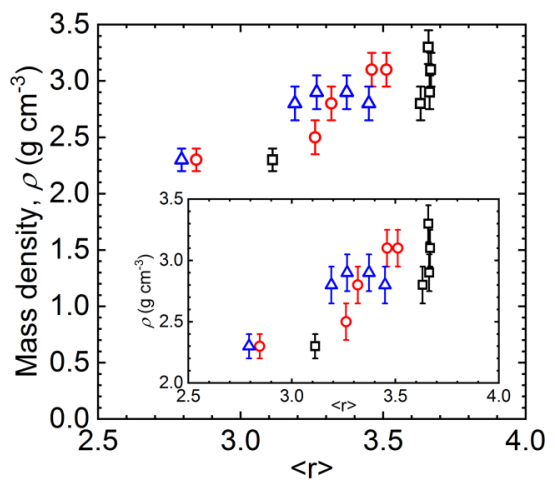

FIG. 7. (a) Coordination number $(\langle r\rangle)$ as a function of at. $\%$ hydrogen, (b) mass density $(\rho)$ as a function of at.\% hydrogen, and (c) $\rho$ as a function of $\langle r\rangle$ for the as-deposited and annealed films. All values are tabulated in Table I. Insets in panels (b) and (c) are the same data in the main figure with a zoomed in ordinate scale.

intrinsic thermal conductivities of the film for relatively thin films as compared to other electrical resistance thermometry techniques, such as $3 \omega$, which was used to measure the thermal conductivity of the amorphous silicon nitride films in Refs. [48-50]. This thermal boundary resistance artifact could explain why the data in Refs. [48-50] show an increase in thermal conductivity with film thickness, where our data are constant over the thickness range of interest in this study, particularly for thicknesses $<100 \mathrm{~nm}$, where thermal boundary resistances have been shown to play a role in $3 \omega$-measured thermal conductivities of PECVD-grown $a-\mathrm{SiN}_{x}: \mathrm{H}$ thin films [50]. This implies that the intrinsic vibrational thermal conductivity of $a-\mathrm{SiN}_{x}: \mathrm{H}$ could in fact be constant with thickness even for the thinner films, supporting our previous conclusion that propagons have negligible contributions to the thermal conductivity of $a-\mathrm{SiN}_{x}: \mathrm{H}$ at room temperature.

There is still a marked and consistent difference between the thermal conductivities of the PECVD-grown $a-\mathrm{SiN}_{x}: \mathrm{H}$ and the LPCVD-grown films. A common difference among these two film sets is the presence of hydrogen in the PECVDgrown films. To further understand the role of hydrogen on the thermal conductivity of $a-\mathrm{SiN}_{x}: \mathrm{H}$, we thermally annealed the samples to remove hydrogen. Three sets of $a-\mathrm{SiN}_{x}: \mathrm{H}$ were chosen to anneal: the $1500 \mathrm{sccm} \mathrm{NH}_{3}$ series, the $9000 \mathrm{sccm}$ $\mathrm{NH}_{3}$ series, and the $18000 \mathrm{sccm} \mathrm{NH} \mathrm{NH}_{3}$ series, representing the low, median, and high $\mathrm{NH}_{3}$ flow rate conditions used in deposition. Samples were annealed in an argon-filled tube furnace for $4 \mathrm{~h}$ at four different annealing temperatures: 650, 775,900 , and $1000{ }^{\circ} \mathrm{C}$. The samples were then characterized for composition via NRA-RBS and FTIR. Additionally, for the nominally 200-nm-thick samples in each $\mathrm{NH}_{3}$ flow rate series, ellipsometry was used to determine the film thickness. Finally, TDTR was used to measure the thermal conductivity of each sample after annealing.

Table I shows the resulting compositions, thicknesses, and thermal conductivities for the nominally 200 -nm-thick samples of each series as deposited and at each annealing temperature. Note that upon annealing, the films shrink significantly in size to compensate for the loss of hydrogen, which is consistent with the increase in density that we observe with annealing in our RBS measurements. This observation is also in agreement with that of previous studies on annealed $a-\mathrm{SiN}_{x}: \mathrm{H}$ films $[82,83]$. The role of the loss of at.\% hydrogen on the coordination number $(\langle r\rangle)$ and density $(\rho)$ is shown in Fig. 7, which plots the coordination number $(\langle r\rangle)$ as a function of at. $\%$ hydrogen in Fig. 7(a) and the density $(\rho)$ as a function of at.\% hydrogen in Fig. 7(b). The loss of hydrogen leads to an increase in coordination number and corresponding increase in density, regardless of $\mathrm{NH}_{3}$ flow rate during deposition. Note, as depicted in Fig. 7(c), which plots $\rho$ as a function of $\langle r\rangle$, the density and network coordination of the $a-\mathrm{SiN}_{x}: \mathrm{H}$ films are directly related to the at.\% hydrogen in the system, which is mainly varied through our annealing procedure.

Figure 8 shows the resulting thermal conductivity as a function of annealing temperature for these samples to reveal

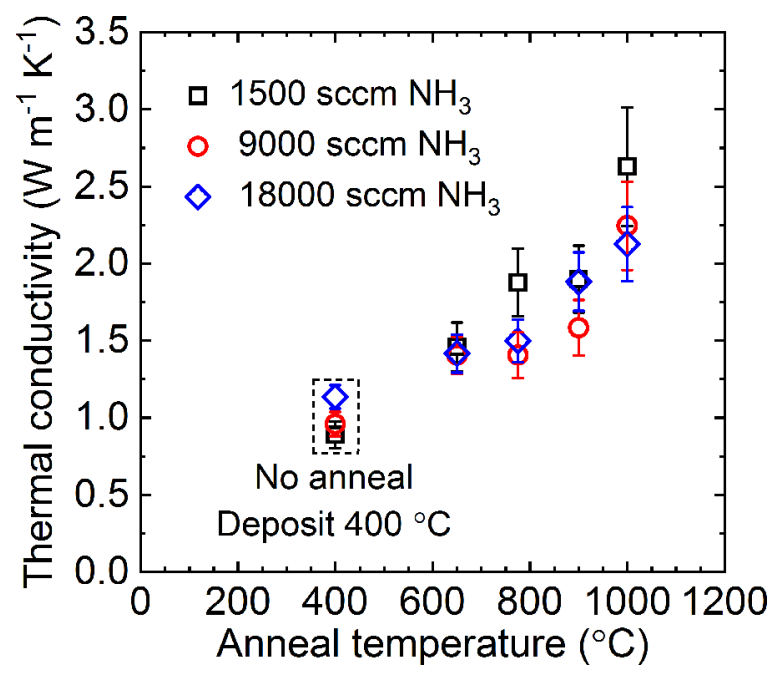

FIG. 8. Measured thermal conductivity $(\kappa)$ vs. annealing temperature for $a-\mathrm{SiN}: \mathrm{H}$ samples for three sample sets: the high and low sccm $\mathrm{NH}_{3}$ cases (1500 and $18000 \mathrm{sccm}$, respectively), and one set with a moderate $\mathrm{sccm}$ of $\mathrm{NH}_{3}$ during growth $(9000 \mathrm{sccm})$. Note, the films that were not annealed were deposited at $400{ }^{\circ} \mathrm{C}$ and thus are positioned on the abscissa accordingly (and encapsulated with the dashed box). 
a systematic increase in thermal conductivity with annealing temperature; at the highest annealing temperature of $1000{ }^{\circ} \mathrm{C}$, $\kappa$ increases by $200-250 \%$ from the as-deposited samples and approaches or exceeds the thermal conductivities of the LPCVD and HTCVD films, which were deposited at temperatures slightly below and above $1000{ }^{\circ} \mathrm{C}$, respectively. For all annealed samples, the measured thermal conductivities showed no observable thickness dependence. This lack of thickness dependence could further support our conclusion that propagons do not contribute to the room temperature thermal conductivity of $a-\mathrm{SiN}_{x}: \mathrm{H}$, including $a$-SiN $x$ with $0 \%$ hydrogen, which is consistent with our results on LPCVDgrown stoichiometric $a-\mathrm{Si}_{3} \mathrm{~N}_{4}$ thin films, and the results on LPCVD-grown $a$-SiN $\mathrm{Silms}_{x}$ reported by Hopkins et al. [45].

Given our discussion above, our results strongly support the hypothesis that diffusons mainly contribute to the thermal transport in amorphous silicon nitride at room temperature. Thus, we now turn our attention to understand why the thermal conductivity of $a-\mathrm{SiN}_{x}: \mathrm{H}$ increases so dramatically as the hydrogen content decreases from annealing. Before characterizing and discussing the role of elemental composition, vibrational bonding, and atomic structure, we return to the PALS analysis to evaluate the porosity changes in the annealed films.

PALS of the annealed $a-\mathrm{SiN}_{x}: \mathrm{H}$ films shows a clear decrease in porosity with annealing, consistent with the increased mass density observed by RBS. We note that the films that were not annealed were deposited at $400{ }^{\circ} \mathrm{C}$ and thus are positioned on the abscissa accordingly (and encapsulated with the dashed boxes); in other words, the films plotted at the abscissa value of $400{ }^{\circ} \mathrm{C}$ are "as deposited" and not annealed after deposition. As shown in Fig. 9(a), the porosity drops precipitously after annealing at $650-800{ }^{\circ} \mathrm{C}$ for all films. The amount of remaining porosity after annealing at $1000{ }^{\circ} \mathrm{C}$ still correlates with the silicon content, albeit with the porosity decreasing as the nitrogen content increases. These results are somewhat consistent with a prior investigation by Uedono et al. [84] where PALS was used to investigate porosity in compressive and tensile PECVDgrown $\mathrm{SiN}_{x}: \mathrm{H}$ films annealed at $1000{ }^{\circ} \mathrm{C}$. For compressive films $\left(2.8 \mathrm{~g} \mathrm{~cm}^{-3}\right.$ and $\left.\% \mathrm{~N}: \% \mathrm{Si}=1\right)$, post-deposition annealing reduced the compressive stress and relaxed the amorphous structure, but they concluded that the intrinsic pores expanded in size and concentration increased. For tensile films $(2.1 \mathrm{~g}$ $\mathrm{cm}^{-3}$ and $\left.\% \mathrm{~N}: \% \mathrm{Si}=0.9\right)$, they observed that while postdeposition annealing decreased the concentration or porosity, the pore sizes remained unchanged. As shown in Fig. 9(b), the fitted spherical pore diameter was also observed to decrease slightly with annealing in some cases. For the 1500 sccm $\mathrm{NH}_{3} a-\mathrm{SiN}_{x}: \mathrm{H}$ film, the pore diameter decreased from $0.62 \mathrm{~nm}$ as deposited to $0.43 \mathrm{~nm}$ after annealing at $1000{ }^{\circ} \mathrm{C}$. However, no decrease in pore diameter was observed for the $18000 \mathrm{sccm} \mathrm{NH} \mathrm{NH}_{3}$ sample, where the pore diameter remained at $0.51 \mathrm{~nm} \pm 0.02 \mathrm{~nm}$ after the $1000{ }^{\circ} \mathrm{C}$ anneal. The decrease in porosity and pore diameter is consistent with both the observed film shrinkage and increased mass density with annealing.

We do note that the anneal temperature at which porosity starts to decrease does show some composition dependence
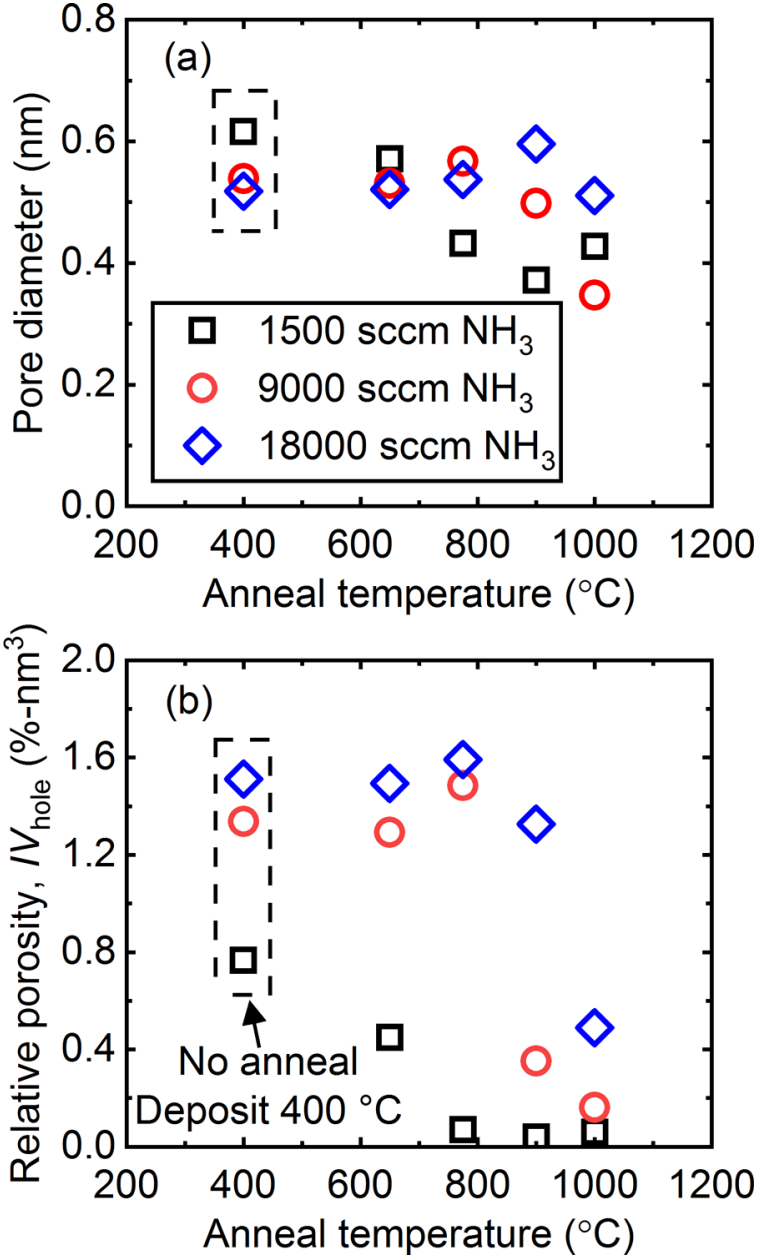

FIG. 9. (a) Spherical pore diameter for PECVD $a$-SiN $x$ :H versus post-deposition annealing temperature and (b) positronium annihilation lifetime spectroscopy (PALS) relative porosity $\left(I V_{\text {hole }}\right)$. In this figure, the statistical error is approximately the size of the symbols. Note, the films that were not annealed were deposited at $400{ }^{\circ} \mathrm{C}$ and thus are positioned on the abscissa accordingly (and encapsulated with the dashed boxes).

with porosity decreasing for the $1500 \mathrm{sccm} \mathrm{NH}_{3}$ films starting at $650{ }^{\circ} \mathrm{C}$, whereas porosity does not significantly decrease until 900 and $1000{ }^{\circ} \mathrm{C}$ for the 9000 and $18000 \mathrm{sccm} \mathrm{NH}_{3}$ films, respectively. As we will show later, the temperature at which porosity collapse starts to occur correlates closely with the hydrogen content in each film, how the hydrogen is incorporated (i.e., $\mathrm{Si}-\mathrm{H}$ versus $\mathrm{N}-\mathrm{H}$ ), and the resulting temperature at which hydrogen loss occurs.

When discussing the porosity dependence on the thermal conductivities of the as-deposited films earlier in this subsection (cf. Figs. 4 and 5), we observed that the slight increase in thermal conductivity of $a-\mathrm{SiN}_{x}: \mathrm{H}$ with $\mathrm{NH}_{3}$ flow rate during growth could not be explained by a change in pore size. But we could not rule out that the porosity of the system, which impacts the mass density, could be impacting the thermal transport. From this, we hypothesize that porosity in the $a-\mathrm{SiN}_{x}: \mathrm{H}$ does not impact vibrational mode scattering, but we could not rule out that porosity could impact the vibrational heat capacities or mode velocities. The PALS 
analysis on the annealed series of samples shown in Fig. 9 adds additional insight into this hypothesis. The relatively constant, if not slightly decreasing pore diameter with increased annealing temperature shown in Fig. 9(a) supported our previous assertion that the pore size does not reduce vibrational thermal transport from diffuson scattering, since we observe a pronounced increase in thermal conductivity with increased annealing temperature (Fig. 8). However, the increase in thermal conductivity with annealing temperature corresponds to a decrease in porosity [Fig. 9(b)], and increase in density (Table I). This is consistent with prior works on density effects on the thermal conductivity of amorphous thin films $[85,86]$, and trends in the thermal conductivity versus density predicted from the minimum limit to thermal conductivity $[87,88]$. An increase in density leading to an increase in thermal conductivity could be due to an increased number density of diffusons or an increase in the mode diffusivity of the diffusons (related to more interactions among diffusons). We rule out the former from our measurements of heat capacity; as we mentioned previously, the heat capacity is determined to range from $\sim 1.8$ to $2 \mathrm{MJ} \mathrm{m}^{-3} \mathrm{~K}^{-1}$ for all $a-\mathrm{SiN}_{x}: \mathrm{H}$ samples, including these annealed samples. Thus, we conclude that the increase in density from annealing leads to an increase in mode diffusivity, which is not driven from an increase in the number of modes, but instead from an increase in the modal interactions. The mechanisms driving this increase in mode interaction is discussed in the following subsections with respect to composition, bonding, and local vibrational structure.

\section{B. Compositional analysis}

To understand the relationship between $\kappa$ and annealing temperature, we turn to the compositional analysis of the postannealed samples. NRA-RBS reveals that the as-deposited samples possess significant differences in stoichiometry stemming from the deposition with varying $\mathrm{NH}_{3}$ flow rates; these differences in stoichiometry are tabulated in Table I. The 1500 sccm $\mathrm{NH}_{3}$ flow rate case proved to be Si-rich with 51.4 at.\% Si and 28.5 at.\% N, while the $18000 \mathrm{sccm} \mathrm{NH} \mathrm{N}_{3}$ case proved to be N-rich with 30.8 at.\% Si and 43.4 at.\% N. However, the hydrogen content did not vary as heavily; in fact, the 9000 sccm NH 3 and 18000 sccm NH 3 cases show nearly identical $\mathrm{H}$ content of $\sim 26$ at.\%, suggesting a limit to the hydrogen content achievable through this deposition procedure. At the low end, the $1500 \mathrm{sccm} \mathrm{NH} \mathrm{NH}_{3}$ series has a hydrogen composition of only $\sim 20$ at.\%. Upon annealing, however, the hydrogen content can be further reduced. Beginning with the $1500 \mathrm{sccm}$ $\mathrm{NH}_{3}$ case, annealing at $650{ }^{\circ} \mathrm{C}$ significantly reduces the hydrogen, from 20.1 to just 2.2 at. \%. The corresponding change in thermal conductivity is 0.89 to $1.46 \mathrm{~W} \mathrm{~m}^{-1} \mathrm{~K}^{-1}$. While a substantial increase, this is still a relatively low thermal conductivity compared to the next annealed cases; at $775^{\circ} \mathrm{C}$ and $900{ }^{\circ} \mathrm{C}$ annealing temperatures, the hydrogen is reduced to just 0.2 at. $\%$ and the corresponding thermal conductivities measured are 1.88 and $1.90 \mathrm{~W} \mathrm{~m}^{-1} \mathrm{~K}^{-1}$, respectively. Annealing out the final, seemingly insignificant, 0.2 at. $\% \mathrm{H}$ at $1000^{\circ} \mathrm{C}$ leads to a significant increase in thermal conductivity, resulting in a measured value of $2.63 \mathrm{~W} \mathrm{~m}^{-1} \mathrm{~K}^{-1}$. This final composition is a Si-heavy $\mathrm{Si}_{0.66} \mathrm{~N}_{0.34}$ stoichiometry. For the
$9000 \mathrm{sccm} \mathrm{NH} \mathrm{N}_{3}$ case, annealing at $650,775,900$, and $1000{ }^{\circ} \mathrm{C}$ diminishes the hydrogen percentage from 26.0 to $9.8,6.2$, 1.2 , and 0 at. $\%$, increasing the thermal conductivity from 0.98 to $1.41,1.41,1.58$, and $2.25 \mathrm{~W} \mathrm{~m}^{-1} \mathrm{~K}^{-1}$, respectively. The final composition in this case is a nearly equal ratio of $\mathrm{Si}$ and $\mathrm{N}, \mathrm{Si}_{0.51} \mathrm{~N}_{0.49}$. Finally, for the $18000 \mathrm{sccm} \mathrm{NH}$ case, annealing at $650,775,900$, and $1000{ }^{\circ} \mathrm{C}$ diminishes the hydrogen percentage from 25.8 to $9.6,7.7,2.7$, and 0 at.\%, increasing the thermal conductivity from 1.14 to $1.42,1.50$, 1.88 , and $2.13 \mathrm{~W} \mathrm{~m}^{-1} \mathrm{~K}^{-1}$, respectively. The final composition in this case is close to a stoichiometric ratio of $\mathrm{Si}$ and $\mathrm{N}$, $\mathrm{Si}_{0.45} \mathrm{~N}_{0.55}$.

Recasting the thermal conductivity as a function of composition- or density-related parameters, Fig. 10 shows $\kappa$ as a function of (a) atomic \% hydrogen, (b) ratio of atomic $\%$ nitrogen to atomic $\%$ silicon $(\% \mathrm{~N}: \% \mathrm{Si})$, (c) coordination number $(\langle r\rangle)$, and (d) mass density $(\rho)$ for the samples listed in Table I. Hydrogen content proves to be a good predictor of the thermal conductivity for all samples regardless of $\mathrm{Si}$ and $\mathrm{N}$ stoichiometry, showing a decreasing trend with increasing hydrogen content. As a function of $\% \mathrm{~N}: \% \mathrm{Si}$, we observe no apparent trend, suggesting that the role of hydrogen in $a-\mathrm{SiN}_{x}: \mathrm{H}$ influences thermal conductivity more so than deviations from $\% \mathrm{~N}: \% \mathrm{Si}=4 / 3$ expected from stoichiometric $a-\mathrm{Si}_{3} \mathrm{~N}_{4}$. This could explain the lack of trend in all the previous literature data shown in Fig. 2 [specifically Fig. 2(b)], in that any unknown or unreported hydrogen content in $a-\mathrm{SiN}_{x}: \mathrm{H}$ samples will strongly dictate the thermal conductivity and negate any dependence on the ratio of atomic $\%$ nitrogen to atomic $\%$ silicon $(\% \mathrm{~N}: \% \mathrm{Si})$.

Expected from the data shown in Fig. 7, since such a strong dependence of thermal conductivity with changes in atomic \% hydrogen is observed, we also show a direct dependence of thermal conductivity with coordination number $(\langle r\rangle)$ in Fig. 10(c) and density $(\rho)$ in Fig. 10(d). The increase in thermal conductivity with increasing coordination number is in agreement with prior reports on $a-\mathrm{Si}[\mathrm{O} / \mathrm{C}]: \mathrm{H}$ [30] and amorphous fluorocarbons [89]. Conceptually, the increase in coordination number is indicative of increasing the covalently bonded Si-N network, which is directly indicative of an increase in elastic properties and sound speeds of the system [89], and, as shown in Fig. 7(c), an increase in density. Beyond the direct contribution of improved elastic properties that increases the thermal conductivity of amorphous materials $[87,88]$, the aforementioned $a-\mathrm{Si}[\mathrm{O} / \mathrm{C}]: \mathrm{H}$ samples showed that increases in coordination number lead to higher vibrational mean free paths through a longer network for heat to traverse $[30,66,90]$. Together, these conclusions further support the results in Section IV A that the thermal conductivity of $a-\mathrm{SiN}_{x}: \mathrm{H}$ is limited by the mode diffusivity of diffusons which can be increased by removing hydrogen, thus increasing network coordination and density of the material.

\section{Vibrational spectroscopy and hydrogen composition}

While RBS gives a direct measurement of the elemental composition of each sample, we use IR spectroscopy to relate the hydrogen reduction observed by NRA-RBS to the specific bonds being both dissociated and formed during annealing. 
(a)

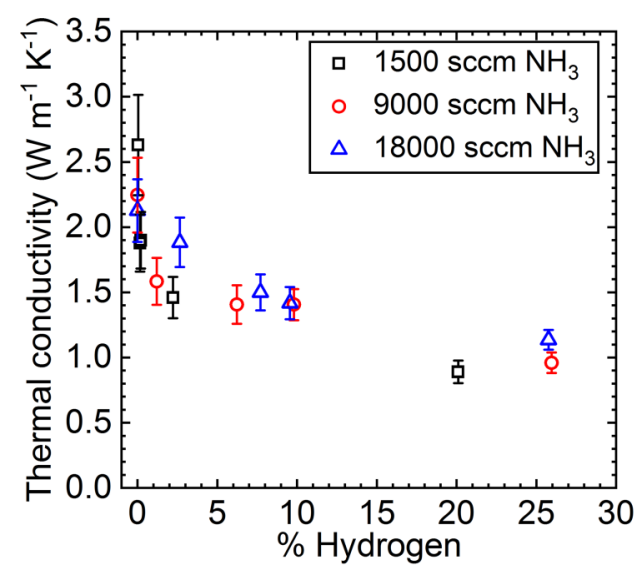

(c)

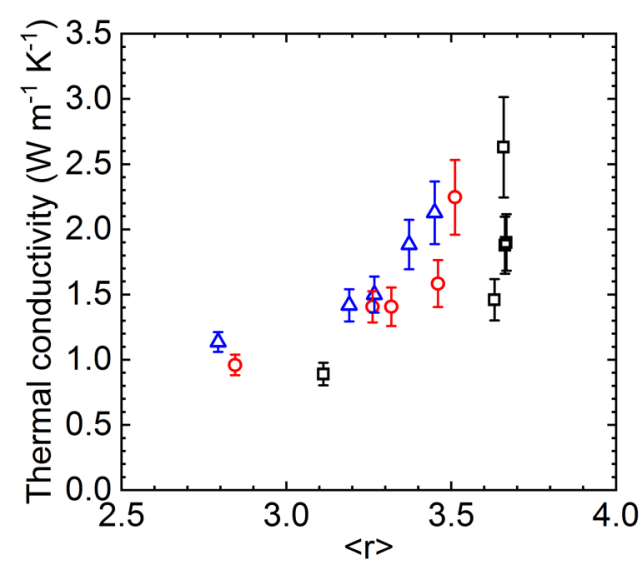

(b)

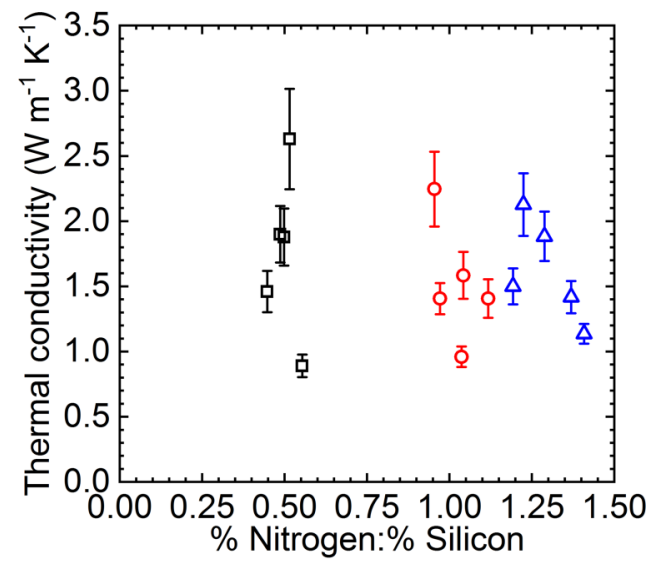

(d)

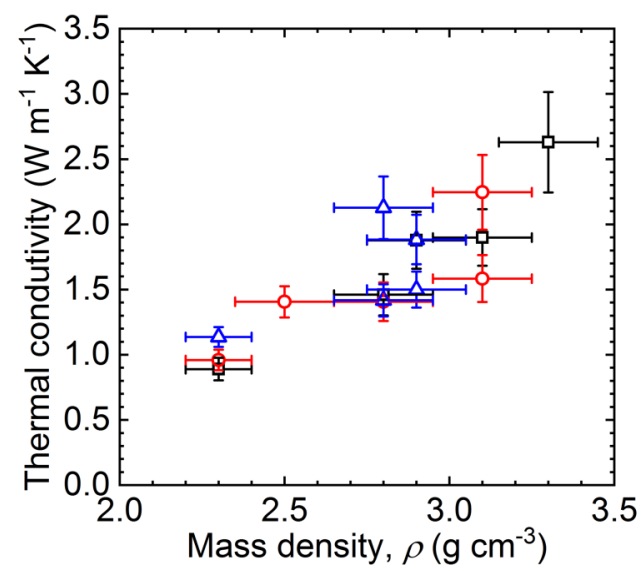

FIG. 10. Measured thermal conductivity vs. (a) atomic \% hydrogen, (b) ratio of atomic \% nitrogen to atomic \% silicon, (c) coordination number $(\langle r\rangle)$, and (d) mass density $(\rho)$ for the same samples listed in Table I.

Figure 11 shows the IR spectra for the samples listed in Table I collected over the range of 400 to $2000 \mathrm{~cm}^{-1}$ via IR-VASE (a)-(c) and 2000 to $4000 \mathrm{~cm}^{-1}$ via transmission FTIR (d)-(f). Specifically, Figs. 11(a) and 11(d) show the absorption spectra for the $1500 \mathrm{sccm} \mathrm{NH}$ sample as-deposited and annealed at various temperatures, Figs. 11(b) and 11(e) show the same information for the $9000 \mathrm{sccm} \mathrm{NH} \mathrm{N}_{3}$ case, and Figs. 11(c) and 11(f) show this for the $18000 \mathrm{sccm} \mathrm{NH}_{3}$ case. The presentation windows for the IR-VASE and FTIR spectra were selected based on differences in sensitivity between the two techniques to specific absorption bands in $a-\mathrm{SiN}_{x}: \mathrm{H}$ and to greater emphasize relative changes to the relevant peaks corresponding to particular bonds.

Referring first to the 400 to $2000 \mathrm{~cm}^{-1}$ window, a strongly IR-sensitive Si-N asymmetric stretching mode $[90,91]$ is observed that is centered around $870-890 \mathrm{~cm}^{-1}$ for all samples. For the as-deposited samples, the absorbance for this band increases with increasing $\mathrm{NH}_{3}$ flow rate consistent with the NRA-RBS analysis showing increased nitrogen content. With annealing, the Si-N band absorbance increases, suggesting that the loss of hydrogen with annealing is the result of hydrogen bond dissociation and the formation of additional Si-N bonding. The increase in $\mathrm{Si}-\mathrm{N}$ absorbance after annealing at $1000^{\circ} \mathrm{C}$, however, scales with the $\mathrm{NH}_{3}$ flow rate with only a slight $6 \%$ increase observed for the $1500 \mathrm{sccm} \mathrm{NH}$ film, a $22 \%$ increase for the $9000 \mathrm{sccm} \mathrm{NH}_{3}$ film, and a $15 \%$ increase for the $18000 \mathrm{sccm} \mathrm{NH}_{3}$ film. As will be shown later, the small increase for the $1500 \mathrm{sccm} \mathrm{NH}$ film is due to hydrogen being incorporated primarily as $\mathrm{Si}-\mathrm{H}$ and the bond dissociation resulting in predominantly $\mathrm{Si}-\mathrm{Si}$ bonding. Unfortunately, $\mathrm{Si}-\mathrm{Si}$ bonds are IR inactive and not observed in IR-VASE or FTIR. For the 9000 and $18000 \mathrm{sccm} \mathrm{NH}_{3}$ films, hydrogen is incorporated as both Si-H and N-H leading to increased Si-N when dissociated via annealing.

With annealing to $1000{ }^{\circ} \mathrm{C}$, the peak maximum for the Si-N asymmetric stretch also increased from $880 \mathrm{~cm}^{-1}$ to $940 \mathrm{~cm}^{-1}$ for the $1500 \mathrm{sccm} \mathrm{NH}$ film, but varied by only $5-10 \mathrm{~cm}^{-1}$ for the other two $a-\mathrm{SiN}_{x}: \mathrm{H}$ films. The large shift for the former could be a result of the hydrogen loss, a change in film stress, or indicative of a shift from a nitrogen-centered planar $\mathrm{N}_{-} \mathrm{Si}_{3}$ stretching motion to a silicon-centered tetrahedral $\mathrm{Si}_{-}-\mathrm{NSi}_{3}$ stretching motion, as proposed by Bandet $e t$ al. [92] and observed by Itoh et al. [93]. Importantly though, the asymmetric Si-N stretching band is observed to broaden with annealing in all cases. This indicates that the observed increase in thermal conductivity with annealing is not due to 
(a)
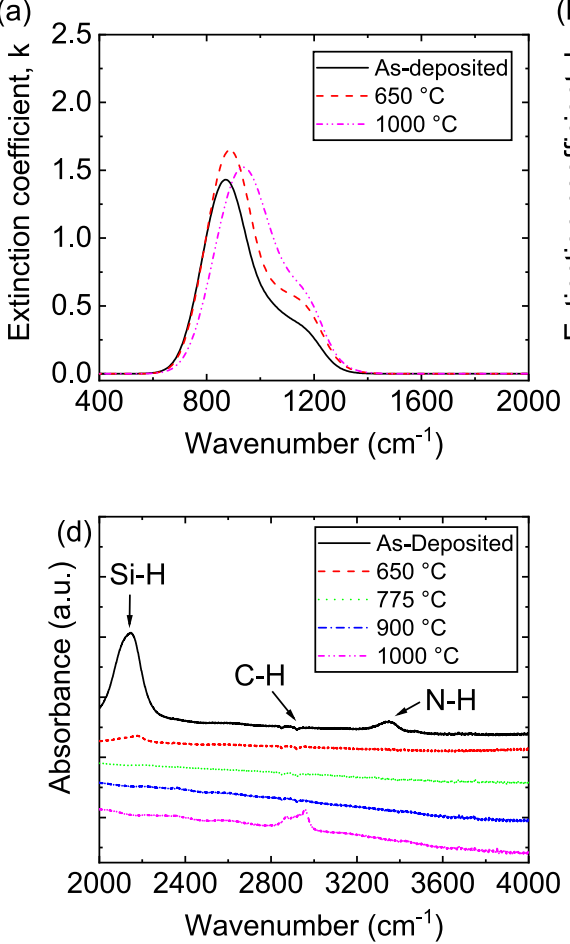

(b)
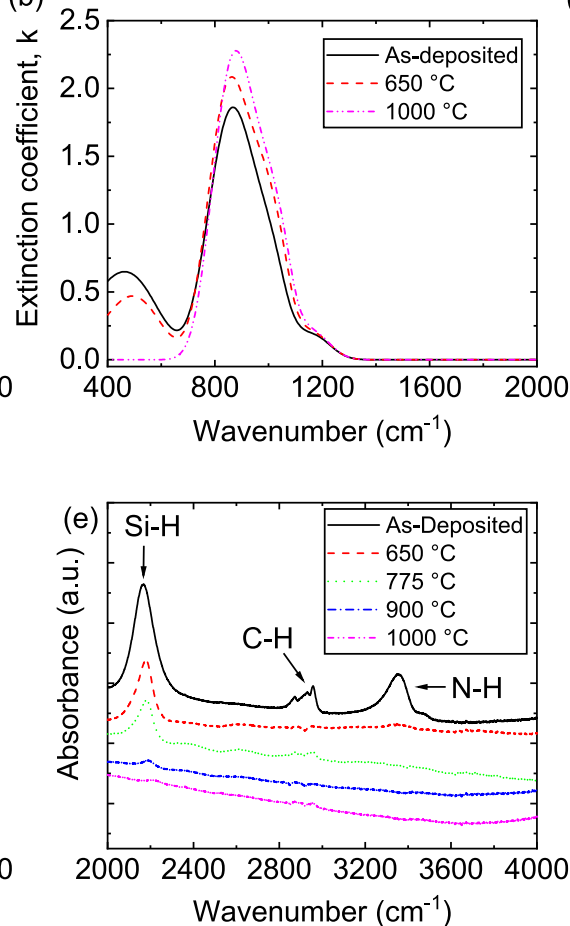

(c)
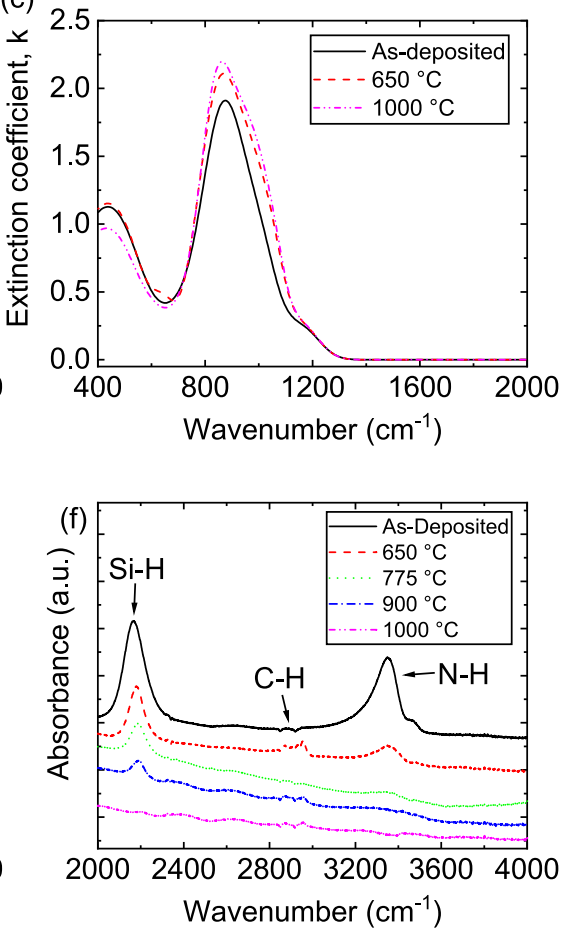

FIG. 11. IR-VASE (top row) and FTIR (bottom row) spectra for as-deposited and annealed $a$-SiN:H samples from 650 to $1000{ }^{\circ} \mathrm{C}$ for the (a), (d) $1500 \mathrm{sccm} \mathrm{NH}_{3}$ series, (b), (e) $9000 \mathrm{sccm} \mathrm{NH}_{3}$ series, and (c), (f) $18000 \mathrm{sccm} \mathrm{NH}_{3}$ series.

increased chemical structural order gained through hydrogen evolution, but instead due to an increase in network bond density as suggested by the previously discussed NRA-RBS analysis.

Closer examination of Figs. 11(a)-11(c) also reveals in all cases a small shoulder on the asymmetric Si-N absorption band centered at $\sim 1200 \mathrm{~cm}^{-1}$, and in some cases an additional peak centered at $440-500 \mathrm{~cm}^{-1}$. The former has been observed in previous studies of $a-\mathrm{SiN}_{x}: \mathrm{H}$ films [94] and attributed to a bending mode in the $\mathrm{Si}-\mathrm{NH}-\mathrm{Si}$ group [91]. However, the continued presence of this peak in the $1000{ }^{\circ} \mathrm{C}$ annealed cases, where RBS confirms no hydrogen presence, suggests this spectral feature may have another structural/nonhydrogen related origin. The peak centered at $440-500 \mathrm{~cm}^{-1}$ has also been previously observed and attributed to a symmetric Si-N stretching or "breathing" mode $[90,95]$. The presence of this lower wavenumber $\mathrm{Si}-\mathrm{N}$ band clearly scales with nitrogen content where it is not observed for the $1500 \mathrm{sccm} \mathrm{NH}_{3}$ film, weakly observed but disappears after annealing for the $9000 \mathrm{sccm} \mathrm{NH}_{3}$ film, and prominently observed before and after annealing for the $18000 \mathrm{sccm} \mathrm{NH}$ film. For dilute nitrogen-doped $a$-Si:H films, Lucovsky et al. [95] have specifically assigned this peak to a planar breathing mode consisting of a nitrogen atom bonded to three $\mathrm{Si}$ atoms with $\mathrm{Si}$ and hydrogen back bonds. Based on this assignment, one could attribute the disappearance of the breathing mode after $1000{ }^{\circ} \mathrm{C}$ annealing for the $9000 \mathrm{sccm} \mathrm{NH}_{3}$ film to the complete loss of hydrogen. Similarly, the total absence of the breathing mode in the $1500 \mathrm{sccm} \mathrm{NH}_{3}$ film may also be related to the lower starting hydrogen content for the film. However, the greater absorbance and continued presence of this band after annealing at $1000{ }^{\circ} \mathrm{C}$ for the $18000 \mathrm{sccm}$ $\mathrm{NH}_{3}$ film suggests the presence of a true $\mathrm{Si}-\mathrm{N}_{4}$ symmetric stretching motion. This would be consistent with the near stoichiometric composition $(\mathrm{N} / \mathrm{Si}=1.33)$ for this film.

For the 2000 to $4000 \mathrm{~cm}^{-1}$ IR window shown in Figs. 11(d)-11(f), Si-H and N-H stretching modes at 2100 $2200 \mathrm{~cm}^{-1}$ and $3350 \mathrm{~cm}^{-1}$ can be respectively observed [90] with a minor C-H stretching mode at $2800-3000 \mathrm{~cm}^{-1}$ also sometimes present and attributed to surface organic or background environmental contamination [68]. For the N-H band, the absorbance for the as-deposited films was observed to increase with increasing $\mathrm{NH}_{3}$ flow rate as perhaps expected. In contrast, the $\mathrm{Si}-\mathrm{H}$ absorbance was observed to remain relatively constant with $\mathrm{NH}_{3}$ flow rate. However, the $\mathrm{Si}-\mathrm{H}$ mode for the as-deposited $1500 \mathrm{sccm} \mathrm{NH}_{3}$ film was centered at $2150 \mathrm{~cm}^{-1}$ and increased slightly to $2175 \mathrm{~cm}^{-1}$ as the $\mathrm{NH}_{3}$ flow rate increased to 9000 and $18000 \mathrm{sccm}$. This has been previously observed in Refs. [95,96] and was attributed to a change in the $\mathrm{Si}-\mathrm{H}$ bond length as the $\mathrm{Si}$ back bonding changed from $\mathrm{Si}_{3}-\mathrm{Si}$ to $\mathrm{N}_{3}-\mathrm{Si}$. In addition, the $\mathrm{Si}-\mathrm{H}$ absorption band for the $1500 \mathrm{sccm} \mathrm{NH}$ film exhibits a larger full width half maximum (FWHM) relative to the higher $\mathrm{NH}_{3}$ flow rate films. In $a$-Si:H, absorption near $2150 \mathrm{~cm}^{-1}$ and $2300 \mathrm{~cm}^{-1}$ has been attributed to the stretching modes of $\mathrm{Si}-\mathrm{H}_{2}$ and/or $\left(\mathrm{Si}-\mathrm{H}_{2}\right)_{n}$ chains $(\mathrm{n} \geqslant 2)$, and $\mathrm{Si}-\mathrm{H}_{3}$ [94,97]. So, the $\mathrm{Si}$ rich stoichiometry and wide FWHM for the $\mathrm{Si}-\mathrm{H}$ band in the 1500 sccm $\mathrm{NH}_{3}$ film suggests a possible mix of $\mathrm{Si}-\mathrm{H}_{2}$ and $\mathrm{Si}-\mathrm{H}_{3}$ bonding in addition to a mix of $\mathrm{Si}$ back bonding (i.e., $\mathrm{Si}_{3}-\mathrm{Si}$ versus $\mathrm{NSi}_{2}-\mathrm{Si}$ ).

Upon annealing to $650{ }^{\circ} \mathrm{C}$, both the $\mathrm{Si}-\mathrm{H}$ and $\mathrm{N}-\mathrm{H}$ bands are significantly reduced in magnitude. The $\mathrm{Si}-\mathrm{H}$ band also 
shifts to a higher wavenumber with annealing, suggesting the formation of additional Si-N back bonds as hydrogen leaves the films. Both observations support the conclusion obtained from NRA-RBS that hydrogen is leaving the film and additional $\mathrm{Si}-\mathrm{N}$ or $\mathrm{Si}-\mathrm{Si}$ bonds are being formed, resulting in an increased coordination number and mass density. For all samples, each subsequent anneal leads to a further decrease in $\mathrm{Si}-\mathrm{H}$ and N-H bond peak intensities. The N-H bond appears to dissociate more readily than the $\mathrm{Si}-\mathrm{H}$ bond, as evidenced by the lower annealing temperature necessary to reduce this peak to level with background noise. This is in agreement with predictions from Yin and Smith [98] based on a free energy model, as well as observations by Chen et al. [1] on similar $a-\mathrm{SiN}_{x}: \mathrm{H}$ films. We find that the N-H peak is reduced to the level of background noise at temperatures of 650,775 , and $900{ }^{\circ} \mathrm{C}$ for the 1500,9000 , and $18000 \mathrm{sccm} \mathrm{NH}_{3}$ cases, respectively, while the $\mathrm{Si}-\mathrm{H}$ peak is not reduced to noise until $775{ }^{\circ} \mathrm{C}$ for the $1500 \mathrm{sccm} \mathrm{NH}_{3}$ case and $1000{ }^{\circ} \mathrm{C}$ for the other two cases. Overall, the FTIR spectra reveal that hydrogen bonding is, within measurement sensitivity, nonexistent when annealed to $1000{ }^{\circ} \mathrm{C}$ for all samples, corroborating RBS conclusions.

The above analysis of the IR spectra suggests that for the $1500 \mathrm{sccm} \mathrm{NH}_{3} a-\mathrm{SiN}_{x}: \mathrm{H}$ film, hydrogen is incorporated primarily as $\mathrm{Si}-\mathrm{H}$ bonding with very little $\mathrm{N}-\mathrm{H}$ bonding. With annealing, hydrogen evolution and film densification occur predominantly via $\mathrm{Si}-\mathrm{H}$ bond dissociation and $\mathrm{Si}-\mathrm{Si}$ bond formation. In contrast, hydrogen is increasingly incorporated via $\mathrm{N}-\mathrm{H}$ bonding for the 9000 and $18000 \mathrm{sccm} \mathrm{NH}_{3}$ films. Due to the increased N-H content for these two films, hydrogen evolution and film densification increasingly occurs via both $\mathrm{Si}-\mathrm{H}$ and $\mathrm{N}-\mathrm{H}$ dissociation and $\mathrm{Si}-\mathrm{N}$ bond formation with some $\mathrm{Si}-\mathrm{Si}$ bond formation still possible. The higher thermal conductivity for the $1500 \mathrm{sccm} \mathrm{NH}_{3} a-\mathrm{SiN}_{x}: \mathrm{H}$ film after annealing at $1000{ }^{\circ} \mathrm{C}$, despite starting with the lowest thermal conductivity, suggests a possible higher heat carrying capacity for $\mathrm{Si}-\mathrm{Si}-\mathrm{Si}$ bonding relative to $\mathrm{Si}-\mathrm{N}-\mathrm{Si}$ bonding. One possible explanation for this may be related to a higher stiffness for $\mathrm{Si}-\mathrm{Si}$ versus $\mathrm{Si}-\mathrm{N}$ bonding. However, the asdeposited $a-\mathrm{SiN}_{x}: \mathrm{H}$ films exhibited a higher Young's modulus and lower thermal conductivity relative to $a$-Si:H. Further, the annealed $1500 \mathrm{sccm} \mathrm{NH}_{3} a-\mathrm{SiN}_{x}: \mathrm{H}$ film exhibited a lower Young's modulus relative to the $18000 \mathrm{sccm} \mathrm{NH}_{3} a-\mathrm{SiN}_{x}: \mathrm{H}$ film (cf. Table IV in the Appendix). An alternative explanation may be a mismatch in vibrational modality between $\mathrm{Si}$ and $\mathrm{N}$ where $\mathrm{Si}$ prefers three-dimensional $\mathrm{sp}^{3}$ bonding and nitrogen instead prefers a planar more $\mathrm{sp}^{2}$ like bonding configuration. This 3D-2D modality mismatch may also explain the lack of thickness-dependent thermal conductivity, which can be attributed to diffuson dominated heat transport [23], observed for the $a-\mathrm{SiN}_{x}: \mathrm{H}$ and $a-\mathrm{SiN}_{x}$ films in this study. We note that this explanation is consistent with the lack of thickness dependent thermal conductivity observed for $a-\mathrm{SiO}_{2}$ $[23,28]$, where there is a $3 \mathrm{D}-1 \mathrm{D}$ bond modality mismatch between $\mathrm{Si}$ and $\mathrm{O}$. It is also consistent with our observations that the addition of up to $\sim 7 \%$ hydrogen to $a$-Si does not eliminate the thickness dependence of thermal conductivity. In this case, hydrogen reduces the mean network connectivity, but does not disrupt the overall 3D network modality in $a-\mathrm{Si}$.

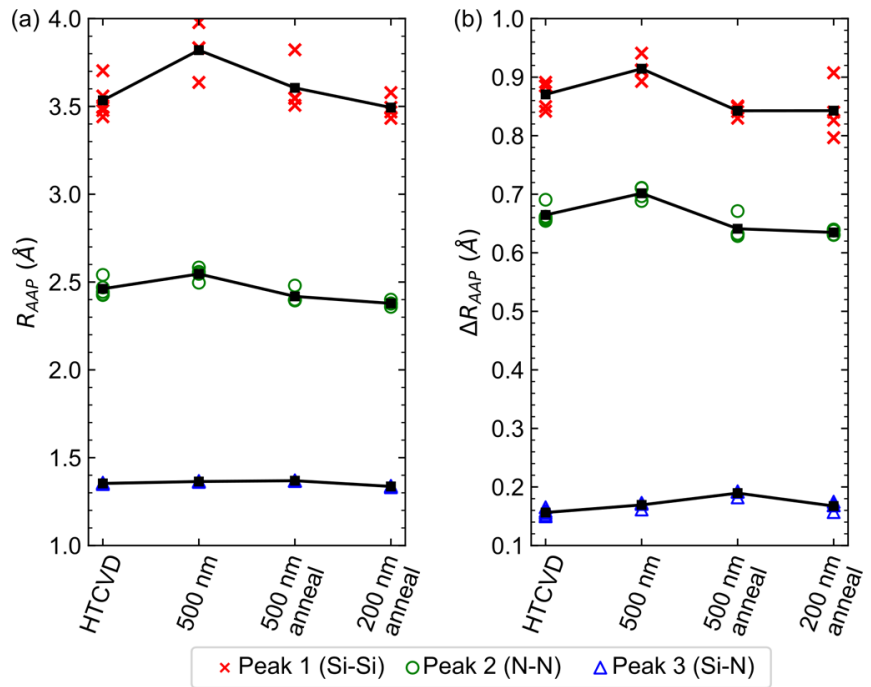

FIG. 12. Extracted (a) $R_{\mathrm{AAP}}$ and (b) $\Delta R_{\mathrm{AAP}}$ from the first three peaks in the RIDP shown in Fig. 3. Markers indicate the raw data and the filled markers are the mean, with the black line included to guide the eye among mean data points. Samples labeled "anneal" were annealed.

\section{Hydrogen effects on average atomic distances}

The impact of adding hydrogen on the average atomic spacing of a stoichiometric $a-\mathrm{Si}_{3} \mathrm{~N}_{4}$ film can be evaluated by comparing the measured average atomic distances, $R_{\mathrm{AAP}}$ [Eq. (2)], and the distribution of these average atomic distances, $\Delta R_{\mathrm{AAP}}$ [Eq. (3)], of the four films on which selected-area electron diffraction was performed. These results are shown in Fig. 12. Comparing the HTCVD $a-\mathrm{Si}_{3} \mathrm{~N}_{4}$ film to the 500-nm-thick as-deposited $18000 \mathrm{sccm} a-\mathrm{SiN}_{x}: \mathrm{H}$ film, the first three average atomic distances increased with the addition of hydrogen, suggesting that $\mathrm{Si}-\mathrm{Si}, \mathrm{N}-\mathrm{N}$, and $\mathrm{Si}-\mathrm{N}$ distances are increased. The mean $\Delta R_{\mathrm{AAP}}$ also increased for all three peaks suggesting that the distribution of average atomic distances is also increased in the presence of hydrogen. This is a direct observation of the increased network bond density in the absence of hydrogen suggested by FTIR and previously discussed in the NRA-RBS analysis.

After annealing the 500-nm-thick as-deposited 18000 sccm $a-\mathrm{SiN}_{x}: \mathrm{H}$ film, and a subsequent reduction in hydrogen composition, the shows a decrease in the average $\mathrm{Si}-\mathrm{Si}$ and $\mathrm{N}-\mathrm{N}$ distances, while the average $\mathrm{Si}-\mathrm{N}$ distances increased. On average, the $\Delta R_{\mathrm{AAP}}$ of the $\mathrm{Si}-\mathrm{Si}$ and $\mathrm{N}-\mathrm{N}$ spacing decreases, meaning that the distribution of average atomic distances became less random, while the $\mathrm{Si}-\mathrm{N}$ increase in $\Delta R_{\mathrm{AAP}}$ indicates a more random distribution of distances. Removal of hydrogen from the films requires recovery of $\mathrm{Si}-\mathrm{N}$ bonds and the physical relaxation of the atomic arrangement. The bond distances indicate that this procedure is occurring and is in agreement with the FTIR analysis, however $\Delta R_{\mathrm{AAP}}$ indicates that the films were incompletely relaxed and showed a lack of order about their central distances. This is again a direct observation of the increased network bond density post annealing suggested by FTIR and previously discussed by NRA-RBS analysis. 
Both the 200- and 500-nm-thick $18000 \mathrm{sccm} a-\mathrm{SiN}_{x}: \mathrm{H}$ films annealed at $1000^{\circ} \mathrm{C}$ show the same trend in $\mathrm{Si}-\mathrm{Si}$ and $\mathrm{N}$ $\mathrm{N}$ average atomic spacing relative to the $500-\mathrm{nm}$ as-deposited sample, indicating an independence on film thickness, consistent with our thickness-independent thermal conductivity measurements. The average Si-N distance of the 200-nm annealed sample was unusually low compared with the other three samples so was deemed as an outlier. The similarities between the 200- and 500-nm-thick 18000 sccm $a$-SiN ${ }_{x}: \mathrm{H}$ films annealed at $1000{ }^{\circ} \mathrm{C}$, and their difference with the 500 -nmthick as-deposited $18000 \mathrm{sccm} a-\mathrm{SiN}_{x}: \mathrm{H}$ film, emphasizes the impact of hydrogen on the distribution of average atomic distances or network bond density, which in turn reflects in the thermal conductivity results: hydrogen incorporation into silicon nitride leads to an increase in average atomic distances, which underpins the resulting decrease in density of the films, and directly translates to a reduction in thermal conductivity.

\section{E. Molecular dynamics simulations and lattice dynamics calculations}

To understand the role of increases in the average atomic distances and resulting density changes on the vibrational thermal transport in amorphous solids (in general), we perform lattice dynamics calculations to determine the diffuson thermal conductivity for amorphous silicon using the widely used Stillinger-Weber (SW) potential. We note that there have been a considerable amount of recent computational works based on atomistic simulations and lattice dynamic calculations that have focused on shedding light on the mode-level vibrational heat conduction in amorphous solids; the readers are referred to Refs. [20,22,24,28,99-102] for detailed pictures of how heat is conducted in disordered materials. In our current work, we specifically focus on the role of average atomic distances on the vibrational thermal transport of diffusonlike vibrations in amorphous solids.
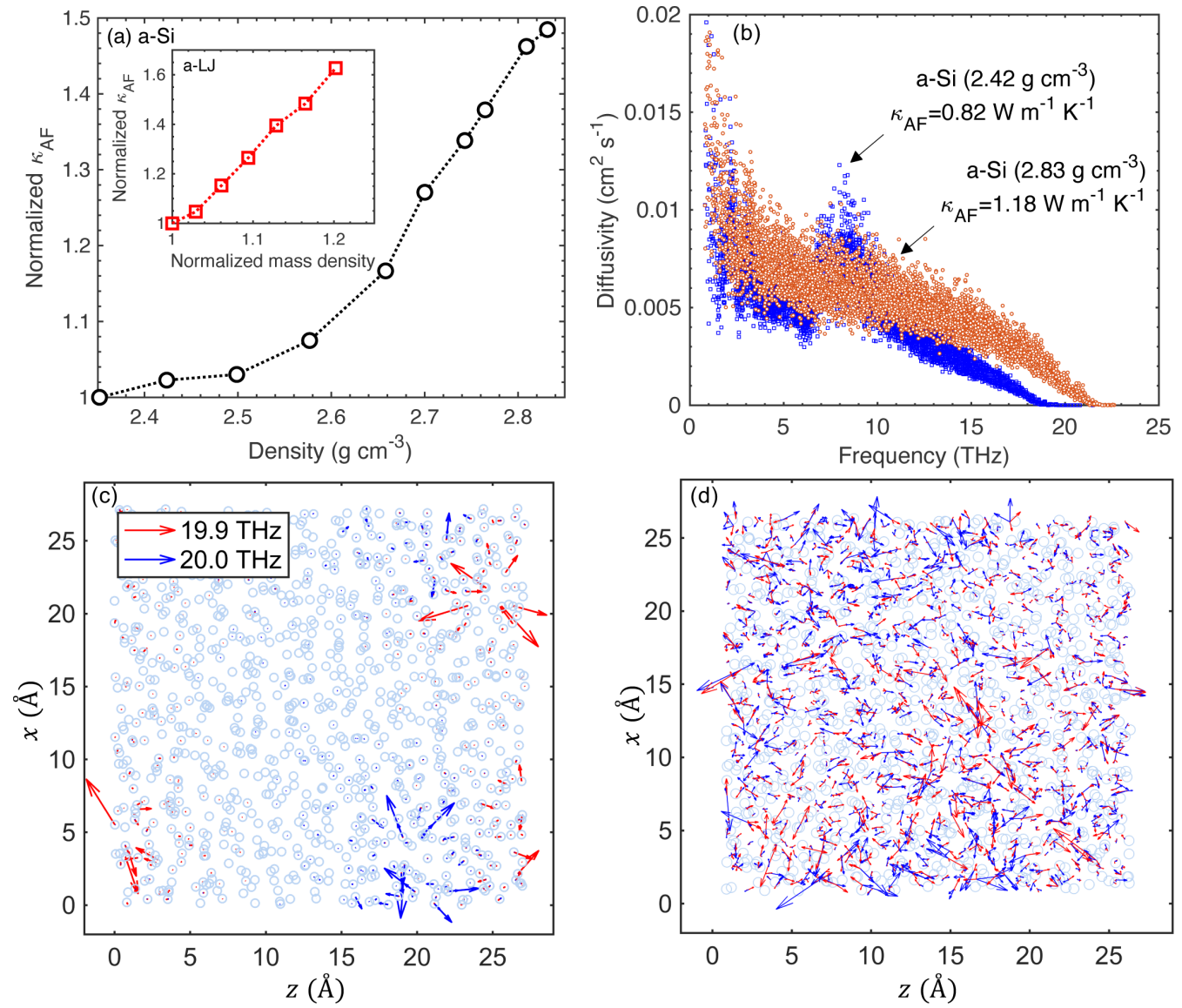

FIG. 13. (a) Thermal conductivity predicted via the Allen and Feldman theory for diffusons in amorphous Stillinger-Weber silicon as a function of mass density. The diffuson-dominated thermal conductivity increases with increasing density, in qualitative agreement with our experimentally observed thermal conductivity increase in our $a-\mathrm{SiN}_{x}: \mathrm{H}$ samples. (inset) To test the generality of these results, we conduct similar calculations for amorphous argon described by the generic Lennard-Jones potential. Similar to the results for our MD-simulated $a$-Si domains, the diffuson contribution to thermal conductivity increases monotonically as a function of mass density. (b) Mode diffusivity calculations from the Allen and Feldman theory for amorphous Stillinger-Weber silicon at $2.42 \mathrm{~g} \mathrm{~cm}^{-3}$ and $2.83 \mathrm{~g} \mathrm{~cm}^{-3}$ densities. Spatial components of the two dimensional eigenvectors for 19.9 and $20.0 \mathrm{THz}$ frequency modes in amorphous Stillinger Weber silicon at (c) $2.42 \mathrm{~g}$ $\mathrm{cm}^{-3}$ and (d) $2.83 \mathrm{~g} \mathrm{~cm}^{-3}$. The blue circles represent silicon atoms. In contrast to the spatial distribution of these modes throughout the higher density case, these modes are predominantly localized in the lower density case. 
The equilibrated amorphous SW-silicon domains are created with molecular dynamics simulations using the meltquench technique as detailed in our previous work [22]. Lattice dynamics calculations are then performed on our SW-silicon domains using the general utility lattice program (GULP) [103]. To calculate the diffuson thermal conductivity, we utilize the Allen and Feldman (AF)-theory for diffusive and nonpropagating modes given as $[104,105]$

$$
\kappa_{\mathrm{AF}}=\sum_{\text {diffusons }} \frac{k_{\mathrm{B}}}{V} D_{\mathrm{AF}, n}\left(\omega_{n}\right),
$$

where $\omega_{n}$ is the frequency of the $n$th diffuson and $D_{\mathrm{AF}, n}$ under the harmonic approximation is calculated as

$$
D_{\mathrm{AF}, n}\left(\omega_{n}\right)=\frac{\pi V^{2}}{\hbar^{2} \omega_{n}^{2}} \sum_{m \neq n}\left|S_{n m}\right|^{2} \delta\left(\omega_{n}-\omega_{m}\right),
$$

where $\left|S_{n m}\right|$ is the heat current operator for the harmonic modes. According to AF theory, the spatial overlap between the eigenvectors of the different modes along with their energetic overlap (i.e., the proximity of the frequencies) dictates the diffusivities of the delocalized modes.

Our results for the calculations of $\kappa_{\mathrm{AF}}$ for amorphous SW-silicon with varying densities is shown in Fig. 13(a). The diffuson-dominated thermal conductivity increases with increasing density, in qualitative agreement with our experimentally observed thermal conductivity increase in our $a-\mathrm{SiN}_{x}: \mathrm{H}$ samples [the generality of these results are demonstrated by the similar trends in thermal conductivity versus mass density that we observe in similar calculations for amorphous Argon described by the generic Lennard-Jones potential, shown in the inset of Fig. 13(a)]. The increase in $\kappa_{\mathrm{AF}}$ for our amorphous SW-silicon is mainly dictated by the overall increase in diffusivities of modes in almost the entire frequency range as shown in Fig. 13(b) for the two different densities. The increase in diffusivities of the modes with density is pronounced at the higher frequencies as schematically demonstrated in Figs. 13(c) and 13(d) where we plot the eigenvectors for the high-frequency modes (at 19.9 and $20.0 \mathrm{THz}$ ) for structures with $2.42 \mathrm{~g} \mathrm{~cm}^{-3}$ and $2.83 \mathrm{~g} \mathrm{~cm}^{-3}$ densities, respectively. We only plot the $x$ and $z$ components of the eigenvectors for clarity for these eigenvectors. Note, these eigenvectors are the closest frequency modes with respect to each other in our amorphous SW-silicon structures and so are energetically more favorable to couple according to the AF theory. As is clear, the spatial separation and localization of these two closest modes suggests that they are locons in the structure with the lower density. Therefore, according to the AF theory, the lack of spatial overlap, even though these modes are energetically close, prevents them from coupling with each other and thus leads to their lowered diffusivities. However, these modes have larger spatial overlap (and also extend throughout the structure) for the higher density structure and possess higher diffusivities. These simulation results provide atomic scale insight into the role of average atomic spacing on the thermal conductivity of nonpropagating modes, in that a decrease in average atomic spacing (resulting in an increase in density) will result in a higher probability of spatial overlap of vibrational modes, which leads to an increase in thermal conductivity. This gives insight into the fundamental heat transport mechanisms that drive the increase in thermal conductivity of amorphous solids with increased density, including that of $a-\mathrm{SiN}_{x}: \mathrm{H}$ with a decrease in hydrogen content.

\section{CONCLUSIONS}

This work details the impact that varying hydrogen composition has on the thermal conductivity of amorphous silicon nitride thin films. To date, inconsistent atomistic characterization of intentionally or unintentionally hydrogenated silicon nitride films has led to discrepancies in the literature of the thermal conductivity of $a-\mathrm{SiN}_{x}: \mathrm{H}$ and thus a void in the understanding of how vibrational energy transport is impacted by hydrogen in amorphous materials. Through extensive chemical, vibrational, and structural analysis in tandem with thermal conductivity measurements, we show that hydrogen incorporation into silicon nitride disrupts the bonding among silicon and nitrogen atoms. This incorporation of hydrogen leads to an increase in average atomic pair distances, as measured via selected-area electron diffraction, which underpins the resulting decrease in density of the films, and directly translates to a reduction in thermal conductivity. We conclude that the vibrational heat transport in $a-\mathrm{SiN}_{x}: \mathrm{H}$ is primarily dominated by diffusonlike modes at room temperature for thicknesses ranging from $50 \mathrm{~nm}$ to $2 \mu \mathrm{m}$. The thermal conductivity of the diffusons in $a-\mathrm{SiN}_{x}: \mathrm{H}$ is a direct function of the hydrogen composition, and is proportional to the density and average atomic pair distances in the $a-\mathrm{SiN}_{x}: \mathrm{H}$. We further support this conclusion through molecular dynamics simulations, and show that an increased density leads to an increased overlap of the diffuson wavefunctions, leading to the increased diffuson thermal conductivity. The original results presented in this work combined with our extensive review of prior reports on the thermal conductivity of $a-\mathrm{SiN}_{x}: \mathrm{H}$ films resolves discrepancies in prior literature and facilitates a more universal understanding of the vibrational heat transport processes in hydrogenated amorphous silicon nitride.

\section{ACKNOWLEDGMENTS}

J.L.B., E.A.S., A.G., J.A.T., and P.E.H. appreciate support from the Office of Naval Research, Grant No. N00014-20-12686 and from the National Science Foundation, Grant No. DMR-EPM-2006231. M.A.G., J.H., and M.M.P. acknowledge support by the NSF under Grant No. DMR-1729086. The authors appreciate the LPCVD films from Professor Aman Haque at The Pennsylvania State University.

\section{APPENDIX}

Tabulated values of thermal conductivity and corresponding physical properties of amorphous silicon nitride films reported in this work and prior literature. 
TABLE II. In-plane thermal conductivities $\left(\kappa_{r}\right)$ and thicknesses $(d)$ of $a$-SiN $x$ samples reported in the literature that were reviewed in Sec. II (note, films deposited via PECVD are assumed as $\left.a-\mathrm{SiN}_{x}: \mathrm{H}\right)$. When reported, growth process, deposition temperature $\left(T_{\mathrm{dep}}\right)$, density $(\rho)$, reported stoichiometry (if assumed, value appears in parentheses), and ratio of $\% \mathrm{~N}$ to $\%$ Si composition based on stoichiometry reported in paper $(\% \mathrm{~N}: \% \mathrm{Si})$ are listed.

\begin{tabular}{|c|c|c|c|c|c|c|c|}
\hline Reference & $\begin{array}{l}\text { Reported stoichiometry } \\
\text { (assumed stoichiometry) }\end{array}$ & Growth process & $\begin{array}{l}T_{\mathrm{dep}} \\
\left({ }^{\circ} \mathrm{C}\right)\end{array}$ & $\begin{array}{c}\rho \\
\left(\mathrm{g} \mathrm{cm}^{-3}\right)\end{array}$ & $\% \mathrm{~N}: \% \mathrm{Si}$ & $\begin{array}{l}\text { Thickness } \\
\text { (nm) }\end{array}$ & $\left(\begin{array}{c}\kappa_{r} \\
\left(\mathrm{~W} \mathrm{~m}^{-1} \mathrm{~K}^{-1}\right)\end{array}\right.$ \\
\hline \multirow[t]{3}{*}{ Mastrangelo et al. [33] } & \multirow[t]{3}{*}{$a-\mathrm{Si}_{1} \mathrm{~N}_{1.1}$} & \multirow[t]{3}{*}{ LPCVD } & 835 & 3 & 1.10 & 2000 & $3.2 \pm 0.5$ \\
\hline & & & 835 & 3 & 1.10 & 3000 & $3.2 \pm 0.5$ \\
\hline & & & 835 & 3 & 1.10 & 4000 & $3.2 \pm 0.5$ \\
\hline Zink and Hellman [34] & $a-\mathrm{Si}_{1} \mathrm{~N}_{1}$ & LPCVD & 835 & 2.9 & 1.0 & 200 & 3.0 \\
\hline \multirow[t]{3}{*}{ Sultan et al. [35] } & \multirow{3}{*}{$a-\mathrm{SiN}_{x}$} & \multirow[t]{3}{*}{ LPCVD } & 835 & 2.9 & & 500 & $2.7 \pm 0.2$ \\
\hline & & & 835 & 2.9 & & 500 & $3.2 \pm 0.15$ \\
\hline & & & 835 & 2.9 & & 500 & 3.2 \\
\hline Sultan et al. [36] & $a-\mathrm{SiN}_{x}$ & LPCVD & 835 & & & 500 & 3.0 \\
\hline Jain and Goodson [37] & $a-\mathrm{SiN}_{x}$ & LPCVD & 850 & & & 1500 & $4.9 \pm 0.7$ \\
\hline \multirow[t]{4}{*}{ Queen and Hellman [38] } & \multirow{4}{*}{$a-\mathrm{SiN}_{1.15}$} & \multirow[t]{4}{*}{ LPCVD } & 835 & 2.68 & 1.15 & 50 & 2.5 \\
\hline & & & 835 & 2.68 & 1.15 & 200 & 4.5 \\
\hline & & & 835 & 2.68 & 1.15 & 50 & 2.0 \\
\hline & & & 835 & 2.68 & 1.15 & 200 & 3.0 \\
\hline \multirow[t]{4}{*}{ Ftouni et al. [39] } & \multirow[t]{2}{*}{$a-\mathrm{Si}_{3} \mathrm{~N}_{4}$} & \multirow[t]{2}{*}{ LPCVD } & & & 1.33 & 50 & 2.9 \\
\hline & & & & & 1.33 & 100 & 3.06 \\
\hline & \multirow[t]{2}{*}{$a-\mathrm{SiN}_{1.1}$} & \multirow[t]{2}{*}{ LPCVD } & & & 1.1 & 50 & 2.5 \\
\hline & & & & & 1 & 100 & 3.8 \\
\hline \multirow[t]{2}{*}{ Zhang and Grigoropoulos [40] } & \multirow[t]{2}{*}{$\mathrm{Si}_{67} \mathrm{~N}_{33}$} & \multirow[t]{2}{*}{ LPCVD } & 835 & & 0.5 & 600 & $13 \pm 1$ \\
\hline & & & 835 & & 0.5 & 1400 & $9 \pm 1$ \\
\hline Irace and Sarro [41] & $a-\mathrm{SiN}_{x}$ & LPCVD & & & & 800 & 1.6 \\
\hline Alam et al. [42] & $a-\mathrm{SiN}_{1-1.1}$ & LPCVD & 820 & 3.1 & $1-1.1$ & 50 & 2.7 \\
\hline Sikora et al. [43] & $a-\mathrm{SiN}_{x}$ & LPCVD & & & & 100 & 10 \\
\hline Bodenschatz et al. [44] & $a-\mathrm{Si}_{3} \mathrm{~N}_{4}$ & LPCVD & & & 1.33 & 100 & $3 \pm 0.2$ \\
\hline \multirow[t]{2}{*}{ Stojanovic et al. [47] } & $a-\mathrm{SiN}_{x}$ & \multirow[t]{2}{*}{ PECVD } & 350 & & 1.33 & 180 & $2.1 \pm 0.2$ \\
\hline & $\left(a-\mathrm{SiN}_{x}: \mathrm{H}\right)$ & & 350 & & 1.33 & 180 & $2.1 \pm 0.15$ \\
\hline \multirow[t]{5}{*}{ Eriksson et al. [32] } & $a-\mathrm{SiN}$ & \multirow[t]{5}{*}{ PECVD } & 300 & 2.2 & & 300 & 3.8 \\
\hline & $\left(a-\mathrm{SiN}_{x}: \mathrm{H}\right)$ & & 300 & 2.2 & & 300 & 4.3 \\
\hline & & & 300 & 2.2 & & 300 & 5.1 \\
\hline & & & 300 & 2.2 & & 500 & 4.8 \\
\hline & & & 300 & 2.2 & & 500 & 4.7 \\
\hline \multirow{5}{*}{ Griffin et al. [51] } & \multirow{5}{*}{$a-\mathrm{Si}_{3} \mathrm{~N}_{4}$} & \multirow[t]{5}{*}{ CVD } & & & 1.33 & 60 & 2.0 \\
\hline & & & & & 1.33 & 210 & 2.0 \\
\hline & & & & & 1.33 & 1200 & 2.0 \\
\hline & & & & & 1.33 & 2820 & 2.0 \\
\hline & & & & & 1.33 & 8500 & 2.0 \\
\hline Lee et al. [52] & $a-\mathrm{SiN}_{x}$ & CVD & & & & 550 & $5.4 \pm 0.5$ \\
\hline
\end{tabular}


TABLE III. Cross-plane thermal conductivities $\left(\kappa_{z}\right)$ and thicknesses $(d)$ of $a$-SiN $x$ samples reported in the literature that were reviewed in Sec. II (note, films deposited via PECVD are assumed as $\left.a-\mathrm{SiN}_{x}: \mathrm{H}\right)$. When reported, growth process, deposition temperature $\left(T_{\mathrm{dep}}\right)$, density $(\rho)$, reported stoichiometry (if assumed, value appears in parentheses), and ratio of $\% \mathrm{~N}$ to $\%$ Si composition based on stoichiometry reported in paper $(\% \mathrm{~N}: \% \mathrm{Si})$ are listed.

\begin{tabular}{|c|c|c|c|c|c|c|c|}
\hline Reference & $\begin{array}{l}\text { Reported stoichiometry } \\
\text { (assumed stoichiometry) }\end{array}$ & Growth process & $\begin{array}{l}T_{\text {dep }} \\
\left({ }^{\circ} \mathrm{C}\right)\end{array}$ & $\begin{array}{c}\rho \\
\left(\mathrm{g} \mathrm{cm}^{-3}\right)\end{array}$ & $\% \mathrm{~N}: \% \mathrm{Si}$ & $\begin{array}{l}\text { Thickness } \\
\text { (nm) }\end{array}$ & $\left(\mathrm{W} \mathrm{m}^{-1} \mathrm{~K}^{-1}\right)$ \\
\hline \multirow[t]{2}{*}{ Hopkins et al. [45] } & \multirow[t]{2}{*}{$a-\mathrm{SiN}_{x}$} & \multirow[t]{2}{*}{ LPCVD } & & & & 46 & $3.1 \pm 0.1$ \\
\hline & & & & & & 232 & $3.5 \pm 0.2$ \\
\hline \multirow[t]{6}{*}{ Bai et al. [46] } & \multirow[t]{6}{*}{$a-\mathrm{Si}_{3} \mathrm{~N}_{4}$} & \multirow[t]{6}{*}{ LPCVD } & 800 & & 1.33 & 37.2 & $1.2 \pm 0.2$ \\
\hline & & & 800 & & 1.33 & 52.9 & $1.7 \pm 0.3$ \\
\hline & & & 800 & & & 76.6 & $1.8 \pm 0.3$ \\
\hline & & & 800 & & & 100.1 & $1.9 \pm 0.4$ \\
\hline & & & 800 & & & 150.5 & $2.0 \pm 0.4$ \\
\hline & & & 800 & & & 200.1 & $2.1 \pm 0.4$ \\
\hline Coquil et al. [48] & $\begin{array}{c}a-\mathrm{SiN} \\
\left(a-\mathrm{SiN}_{x}: \mathrm{H}\right)\end{array}$ & PECVD & & & & 500 & $1.2 \pm 0.4$ \\
\hline \multirow[t]{5}{*}{ Bogner et al. [49] } & $a-\mathrm{Si}_{3} \mathrm{~N}_{4}$ & \multirow[t]{5}{*}{ PECVD } & & & 1.33 & 298 & $0.8 \pm 0.1$ \\
\hline & $\left(a-\mathrm{SiN}_{x}: \mathrm{H}\right)$ & & & & 1.33 & 500 & $1.2 \pm 0.1$ \\
\hline & & & & & 1.33 & 601 & $1.3 \pm 0.1$ \\
\hline & & & & & 1.33 & 698 & $1.5 \pm 0.1$ \\
\hline & & & & & 1.33 & 1001 & $1.7 \pm 0.1$ \\
\hline \multirow[t]{5}{*}{ Lee and Cahill [50] } & $a-\mathrm{Si}_{1} \mathrm{~N}_{1.1}$ & \multirow{5}{*}{ PECVD } & 300 & 2.2 & 1.1 & 20 & 0.5 \\
\hline & $\left(a-\mathrm{SiN}_{x}: \mathrm{H}\right)$ & & 300 & 2.2 & 1.1 & 40 & 0.6 \\
\hline & & & 300 & 2.2 & 1.1 & 60 & 0.7 \\
\hline & & & 300 & 2.2 & 1.1 & 120 & 0.8 \\
\hline & & & 300 & 2.2 & 1.1 & 250 & 0.7 \\
\hline Lee and Cahill [50] & $\begin{array}{c}a-\mathrm{Si}_{1} \mathrm{~N}_{1.1} \\
\left(a-\mathrm{SiN}_{x}: \mathrm{H}\right)\end{array}$ & APCVD & 900 & 2.8 & 1.1 & 180 & 1.4 \\
\hline \multirow[t]{3}{*}{ Govorkov et al. [53] } & \multirow[t]{3}{*}{$a-\mathrm{Si}_{3} \mathrm{~N}_{4}$} & \multirow[t]{3}{*}{ Sputtering } & 23 & & 1.33 & 100 & 1.2 \\
\hline & & & 23 & & 1.33 & 210 & 1.2 \\
\hline & & & 23 & & 1.33 & 420 & 1.2 \\
\hline \multirow[t]{13}{*}{ Marconnet et al. [54] } & \multirow[t]{13}{*}{$a-\mathrm{SiN}_{x}$} & \multirow[t]{13}{*}{ Sputtering } & 23 & & 1.2 & 400 & $2.1 \pm 0.2$ \\
\hline & & & 600 & & 1.2 & 400 & $2.2 \pm 0.2$ \\
\hline & & & 700 & & 1.2 & 400 & $2.5 \pm 0.2$ \\
\hline & & & 800 & & 1.2 & 400 & $2.4 \pm 0.2$ \\
\hline & & & 900 & & 1.2 & 400 & $2.6 \pm 0.3$ \\
\hline & & & 1000 & & 1.2 & 400 & $2.6 \pm 0.3$ \\
\hline & & & 1100 & & 1.2 & 400 & $2.7 \pm 0.3$ \\
\hline & & & 1000 & & 1.27 & 400 & $2.4 \pm 0.2$ \\
\hline & & & 1000 & & 1.0 & 400 & $2.3 \pm 0.2$ \\
\hline & & & 1000 & & 0.96 & 400 & $2.1 \pm 0.2$ \\
\hline & & & 1000 & & 0.94 & 400 & $2.2 \pm 0.2$ \\
\hline & & & 1000 & & 0.7 & 400 & $1.7 \pm 0.2$ \\
\hline & & & 1000 & & 0.6 & 400 & $1.3 \pm 0.1$ \\
\hline
\end{tabular}




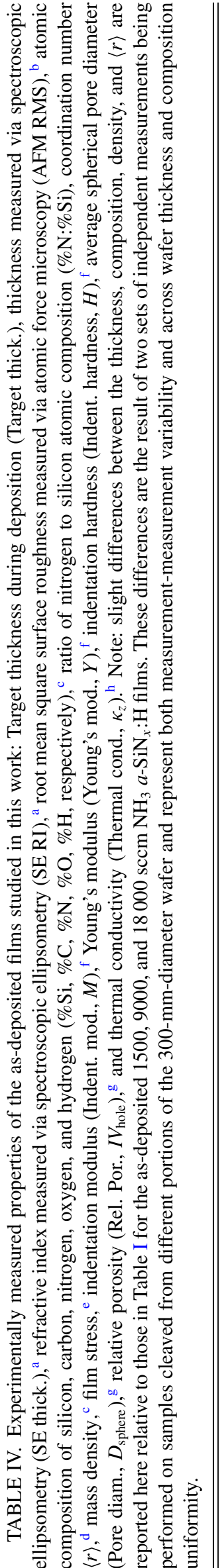

\begin{tabular}{|c|c|}
\hline 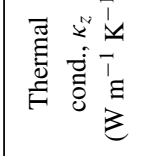 & 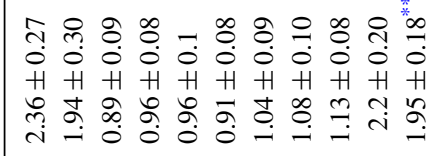 \\
\hline 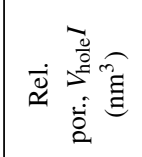 & 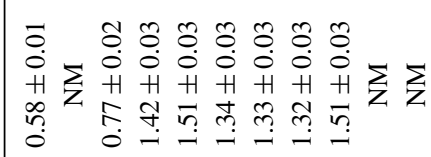 \\
\hline 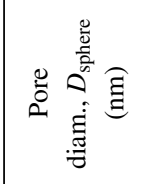 & 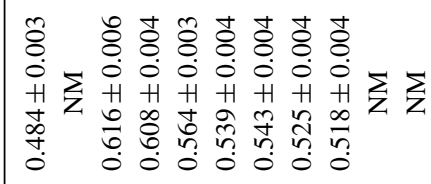 \\
\hline 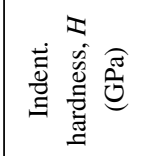 & 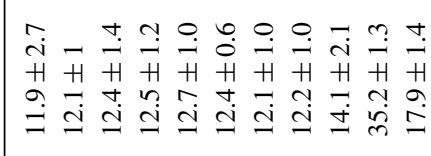 \\
\hline 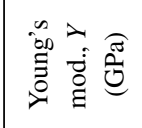 & 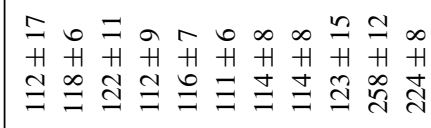 \\
\hline 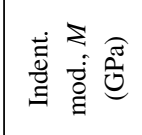 & 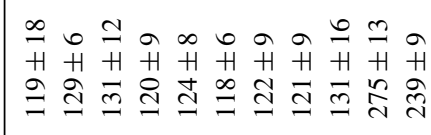 \\
\hline 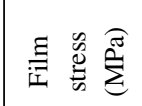 & 莎 \\
\hline 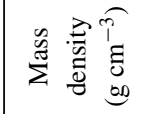 & 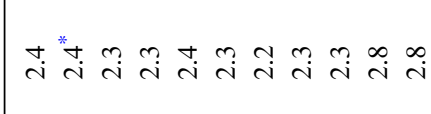 \\
\hline$\Xi$ & 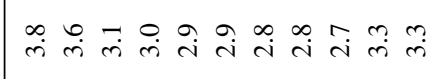 \\
\hline $\begin{array}{l}\vec{n} \\
0 \\
\ddot{z} \\
0\end{array}$ & $\overleftrightarrow{z} \frac{\mathbb{z}}{z} \dot{0}: 0$. \\
\hline$s^{2}$ & 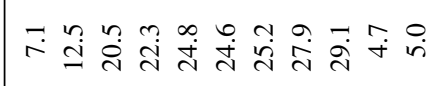 \\
\hline $\begin{array}{l}0 \\
8\end{array}$ & 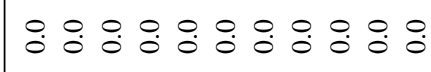 \\
\hline $\begin{array}{c}z_{0} \\
s^{\circ}\end{array}$ & 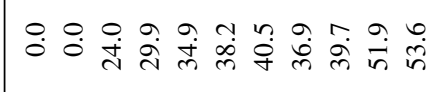 \\
\hline$b^{\circ}$ & $::: \circ:::::::$ \\
\hline $\bar{c}$ & 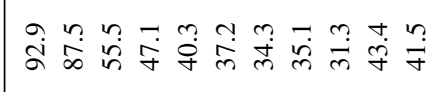 \\
\hline 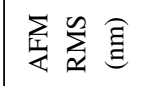 & I \\
\hline & भै \\
\hline 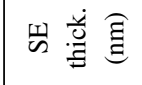 & 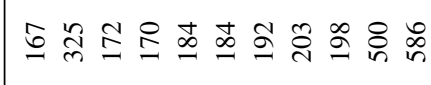 \\
\hline 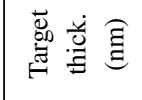 & 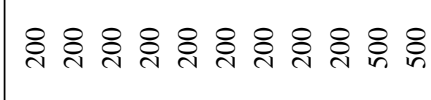 \\
\hline & 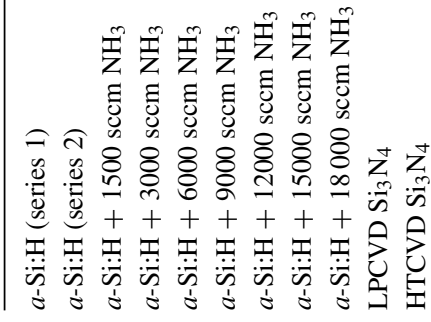 \\
\hline
\end{tabular}

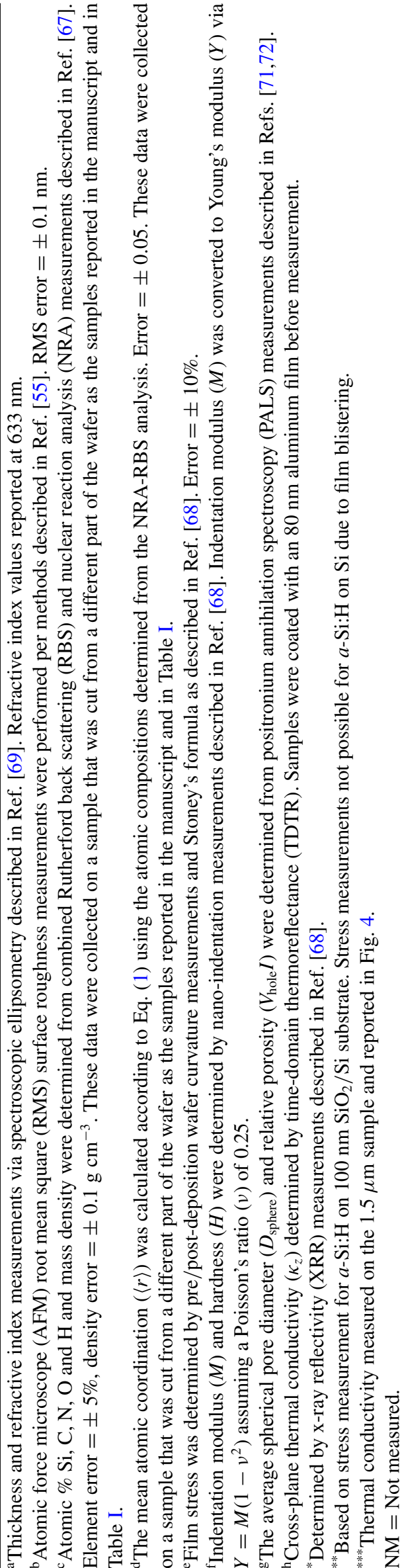


[1] J. Chen, M. Niu, J. Calvin, M. Asplund, S. W. King, B. F. Woodfield, and A. Navrotsky, J. Am. Ceram. Soc. 101, 2017 (2018).

[2] A. E. Kaloyeros, F. A. Jové, J. Goff, and B. Arkles, ECS J. Solid State Sci. Techn. 6, P691 (2017).

[3] B. D. Hatton, K. Landskron, W. J. Hunks, M. R. Bennett, D. Shukaris, D. D. Perovic, and G. A. Ozin, Materials Today 9, 22 (2006)

[4] S. K. Estreicher, Materials Today 6, 26 (2003).

[5] Z. Yang, M. Gao, W. Wu, X. Yang, X. W. Sun, J. Zhang, H.-C. Wang, R.-S. Liu, C.-Y. Han, H. Yang, and W. Li, Materials Today 24, 69 (2019).

[6] R. Raiteri, M. Grattarola, and R. Berger, Materials Today 5, 22 (2002).

[7] R. W. Miles, G. Zoppi, and I. Forbes, Materials Today 10, 20 (2007).

[8] J.-F. Lelièvre, E. Fourmond, A. Kaminski, O. Palais, D. Ballutaud, and M. Lemiti, Sol. Energy Mater. Sol. Cells 93, 1281 (2009).

[9] B. Swatowska and T. Stapinski, Vacuum 82, 942 (2008).

[10] J. Yoo, J. So, G. Yu, and J. Yi, Sol. Energy Mater. Sol. Cells 95, 7 (2011).

[11] F. Massines, J. Silva, J.-F. Lelièvre, R. Bazinette, J. Vallade, P. Lecouvreur, and S. Pouliquen, Plasma Proc. Polymers 13, 170 (2016).

[12] S. Duttagupta, F. Ma, B. Hoex, T. Mueller, and A. G. Aberle, Energy Procedia 15, 78 (2012).

[13] J. Holt, D. Goodwin, A. Gabor, F. Jiang, M. Stavola, and H. A. Atwater, Thin Solid Films 430, 37 (2003).

[14] V. Verlaan, C. H. M. van der Werf, Z. S. Houweling, I. G. Romijn, A. W. Weeber, H. F. W. Dekkers, H. D. Goldbach, and R. E. I. Schropp, Prog. Photovoltaics: Res. Appl. 15, 563 (2007).

[15] Y. Kuo, Vacuum 51, 741 (1998).

[16] L. Wang, H. Qin, W. Zhang, L. Zhang, and D. Yan, Thin Solid Films 545, 514 (2013).

[17] J. Yota, ECS Transactions 35, 229 (2011).

[18] F. de Brito Mota, J. F. Justo, and A. Fazzio, J. Appl. Phys. 86, 1843 (1999).

[19] C. Boehme and G. Lucovsky, J. Appl. Phys. 88, 6055 (2000).

[20] P. B. Allen, J. L. Feldman, J. Fabian, and F. Wooten, Philos. Mag. B 79, 1715 (1999).

[21] J. L. Feldman, M. D. Kluge, P. B. Allen, and F. Wooten, Phys. Rev. B 48, 12589 (1993).

[22] A. Giri, B. F. Donovan, and P. E. Hopkins, Phys. Rev. Mater. 2, 056002 (2018).

[23] J. L. Braun, C. H. Baker, A. Giri, M. Elahi, K. Artyushkova, T. E. Beechem, P. M. Norris, Z. C. Leseman, J. T. Gaskins, and P. E. Hopkins, Phys. Rev. B 93, 140201(R) (2016).

[24] M. C. Wingert, J. Zheng, S. Kwon, and R. Chen, Semicond. Sci. Technol. 31, 113003 (2016).

[25] S. Kwon, J. Zheng, M. C. Wingert, S. Cui, and R. Chen, ACS Nano, ACS Nano 11, 2470 (2017).

[26] T. Kim, J. Moon, and A. J. Minnich, Origin of micron-scale propagation lengths of heat-carrying acoustic excitations in amorphous silicon (2020), arXiv:2007.15777.

[27] J. Moon, R. P. Hermann, M. E. Manley, A. Alatas, A. H. Said, and A. J. Minnich, Phys. Rev. Mater. 3, 065601 (2019).

[28] J. M. Larkin and A. J. H. McGaughey, Phys. Rev. B 89, 144303 (2014).
[29] K. T. Regner, D. P. Sellan, Z. Su, C. H. Amon, A. J. H. McGaughey, and J. A. Malen, Nat. Commun. 4, 1640 (2013).

[30] J. L. Braun, S. W. King, A. Giri, J. T. Gaskins, M. Sato, T. Fujiseki, H. Fujiwara, and P. E. Hopkins, Appl. Phys. Lett. 109, 191905 (2016).

[31] S. V. Garimella, Microelectron. J. 37, 1165 (2006).

[32] P. Eriksson, J. Y. Andersson, and G. Stemme, J. Microelectromech. Syst. 6, 55 (1997).

[33] C. H. Mastrangelo, Y.-C. Tai, and R. S. Muller, Sensors Actuators A: Phys. 23, 856 (1990).

[34] B. Zink and F. Hellman, Solid State Commun. 129, 199 (2004).

[35] R. Sultan, A. D. Avery, J. M. Underwood, S. J. Mason, D. Bassett, and B. L. Zink, Phys. Rev. B 87, 214305 (2013).

[36] R. Sultan, A. D. Avery, G. Stiehl, and B. L. Zink, J. Appl. Phys. 105, 043501 (2009).

[37] A. Jain and K. E. Goodson, J. Heat Transfer 130, 102402 (2008).

[38] D. R. Queen and F. Hellman, Rev. Sci. Instrum. 80, 063901 (2009).

[39] H. Ftouni, C. Blanc, D. Tainoff, A. D. Fefferman, M. Defoort, K. J. Lulla, J. Richard, E. Collin, and O. Bourgeois, Phys. Rev. B 92, 125439 (2015).

[40] X. Zhang and C. P. Grigoropoulos, Rev. Sci. Instrum. 66, 1115 (1995).

[41] A. Irace and P. M. Sarro, Sensors Actuators A: Phys. 76, 323 (1999).

[42] M. T. Alam, M. P. Manoharan, M. A. Haque, C. Muratore, and A. Voevodin, J. Micromech. Microeng. 22, 045001 (2012).

[43] A. Sikora, H. Ftouni, J. Richard, C. Hébert, D. Eon, F. Omnès, and O. Bourgeois, Rev. Sci. Instrum. 83, 054902 (2012).

[44] N. Bodenschatz, A. Liemert, S. Schnurr, U. Wiedwald, and P. Ziemann, Rev. Sci. Instrum. 84, 084904 (2013).

[45] P. E. Hopkins, J. R. Serrano, L. M. Phinney, S. P. Kearney, T. W. Grasser, and C. T. Harris, J. Heat Transfer 132, 081302 (2010).

[46] S. Bai, Z. Tang, Z. Huang, and J. Yu, IEEE Trans. Industr. Electron. 56, 3238 (2009)

[47] N. Stojanovic, J. Yun, E. B. K. Washington, J. M. Berg, M. W. Holtz, and H. Temkin, J. Microelectromech. Syst. 16, 1269 (2007).

[48] T. Coquil, E. K. Richman, N. J. Hutchinson, S. H. Tolbert, and L. Pilon, J. Appl. Phys. 106, 034910 (2009).

[49] M. Bogner, A. Hofer, G. Benstetter, H. Gruber, and R. Y. Fu, Thin Solid Films 591, 267 (2015).

[50] S.-M. Lee and D. G. Cahill, J. Appl. Phys. 81, 2590 (1997).

[51] A. J. Griffin, F. R. Brotzen, and P. J. Loos, J. Appl. Phys. 76, 4007 (1994)

[52] B. Lee, J. S. Lee, S. U. Kim, K. Kim, O. Kwon, S. Lee, J. H. Kim, and D. S. Lim, J. Vac. Sci. Technol. B 27, 2408 (2009).

[53] S. Govorkov, W. Ruderman, M. W. Horn, R. B. Goodman, and M. Rothschild, Rev. Sci. Instrum. 68, 3828 (1997).

[54] A. Marconnet, M. Panzer, S. Yerci, S. Minissale, X. Wang, X. Zhang, L. Dal Negro, and K. E. Goodson, Appl. Phys. Lett. 100, 051908 (2012).

[55] J. T. Gaskins, P. E. Hopkins, D. R. Merrill, S. R. Bauers, E. Hadland, D. C. Johnson, D. Koh, J. H. Yum, S. Banerjee, B. J. Nordell, M. M. Paquette, A. N. Caruso, W. A. Lanford, P. Henry, L. Ross, H. Li, L. Li, M. French, A. M. Rudolph, and S. W. King, ECS J. Solid State Sci. Technol. 6, N189 (2017). 
[56] E. T. Swartz and R. O. Pohl, Rev. Mod. Phys. 61, 605 (1989).

[57] P. E. Hopkins, ISRN Mech. Eng. 2013, 982586 (2013).

[58] A. Giri and P. E. Hopkins, Adv. Funct. Mater. 30, 1903857 (2020).

[59] D. G. Cahill, Rev. Sci. Instrum. 61, 802 (1990).

[60] D. G. Cahill, Rev. Sci. Instrum. 75, 5119 (2004).

[61] A. J. Schmidt, Ann. Rev. Heat Transfer 16, 159 (2013).

[62] E. A. Scott, J. T. Gaskins, S. W. King, and P. E. Hopkins, APL Mater. 6, 058302 (2018).

[63] J. A. Tomko, D. H. Olson, A. Giri, J. T. Gaskins, B. F. Donovan, S. M. O’Malley, and P. E. Hopkins, Langmuir 35, 2106 (2019).

[64] X. Liu, J. L. Feldman, D. G. Cahill, R. S. Crandall, N. Bernstein, D. M. Photiadis, M. J. Mehl, and D. A. Papaconstantopoulos, Phys. Rev. Lett. 102, 035901 (2009).

[65] H.-S. Yang, D. G. Cahill, X. Liu, J. L. Feldman, R. S. Crandall, B. A. Sperling, and J. R. Abelson, Phys. Rev. B 81, 104203 (2010).

[66] B. Cossou, S. Jacques, G. Couégnat, S. W. King, L. Li, W. A. Lanford, G. Bhattarai, M. Paquette, and G. Chollon, Thin Solid Films 681, 47 (2019).

[67] W. A. Lanford, M. Parenti, B. J. Nordell, M. M. Paquette, A. N. Caruso, M. Mäntymäki, J. Hämäläinen, M. Ritala, K. B. Klepper, V. Miikkulainen, O. Nilsen, W. Tenhaeff, N. Dudney, D. Koh, S. K. Banerjee, E. Mays, J. Bielefeld, and S. W. King, Nucl. Instrum. Methods Phys. Res. Sec. B 371, 211 (2016).

[68] S. W. King, J. Bielefeld, G. Xu, W. A. Lanford, Y. Matsuda, R. H. Dauskardt, N. Kim, D. Hondongwa, L. Olasov, B. Daly, G. Stan, M. Liu, D. Dutta, and D. Gidley, J. Non-Cryst. Solids 379, 67 (2013).

[69] B. J. Nordell, S. Karki, T. D. Nguyen, P. Rulis, A. N. Caruso, S. S. Purohit, H. Li, S. W. King, D. Dutta, D. Gidley, W. A. Lanford, and M. M. Paquette, J. Appl. Phys. 118, 035703 (2015).

[70] M. Milosevic and S. W. King, J. Appl. Phys. 112, 093514 (2012).

[71] D. W. Gidley, W. E. Frieze, T. L. Dull, A. F. Yee, E. T. Ryan, and H.-M. Ho, Phys. Rev. B 60, R5157 (1999).

[72] D. W. Gidley, H.-G. Peng, and R. S. Vallery, Annu. Rev. Mater. Res. 36, 49 (2006).

[73] J. L. Braun, C. M. Rost, M. Lim, A. Giri, D. H. Olson, G. N. Kotsonis, G. Stan, D. W. Brenner, J.-P. Maria, and P. E. Hopkins, Adv. Mater. 30, 1805004 (2018).

[74] A. J. Schmidt, R. Cheaito, and M. Chiesa, Rev. Sci. Instrum. 80, 094901 (2009).

[75] J. Liu, J. Zhu, M. Tian, X. Gu, A. Schmidt, and R. Yang, Rev. Sci. Instrum. 84, 034902 (2013).

[76] C. Wei, X. Zheng, D. G. Cahill, and J.-C. Zhao, Rev. Sci. Instrum. 84, 071301 (2013).

[77] D. H. Olson, C. M. Rost, J. T. Gaskins, C. J. Szwejkowski, J. L. Braun, and P. E. Hopkins, IEEE Trans. Comp. Packag. Manufact. Technol. 9, 51 (2019).

[78] M. Rahman, M. Shahzadeh, P. Braeuninger-Weimer, S. Hofmann, O. Hellwig, and S. Pisana, J. Appl. Phys. 123, 245110 (2018).

[79] T. Aiyama, T. Fukunaga, K. Niihara, T. Hirai, and K. Suzuki, J. Non-Cryst. Solids 33, 131 (1979).
[80] M. Misawa, T. Fukunaga, K. Niihara, T. Hirai, and K. Suzuki, J. Non-Cryst. Solids 34, 313 (1979).

[81] A. Uedono, K. Ikeuchi, T. Otsuka, K. Ito, K. Yamabe, M. Kohno, T. Moriya, N. Okumura, T. Nakanishi, T. Arikado, T. Ohdaira, and R. Suzuki, Appl. Phys. Lett. 88, 252107 (2006).

[82] R. Bousbih, W. Dimassi, I. Haddadi, and H. Ezzaouia, Physica Status Solidi (C) 9, 2189 (2012).

[83] S. P. Singh, P. Srivastava, S. Ghosh, S. A. Khan, and G. V. Prakash, J. Phys.: Condens. Matter 21, 095010 (2009).

[84] A. Uedono, K. Ito, T. Narumi, M. Sometani, K. Yamabe, Y. Miyagawa, T. Murata, K. Honda, N. Hattori, M. Matsuura, K. Asai, T. Ohdaira, and R. Suzuki, J. Appl. Phys. 102, 064513 (2007).

[85] C. S. Gorham, J. T. Gaskins, G. N. Parsons, M. D. Losego, and P. E. Hopkins, Appl. Phys. Lett. 104, 253107 (2014).

[86] M. E. DeCoster, K. E. Meyer, B. D. Piercy, J. T. Gaskins, B. F. Donovan, A. Giri, N. A. Strnad, D. M. Potrepka, A. A. Wilson, M. D. Losego, and P. E. Hopkins, Thin Solid Films 650, 71 (2018).

[87] D. G. Cahill, S. K. Watson, and R. O. Pohl, Phys. Rev. B 46 , 6131 (1992).

[88] D. G. Cahill and R. Pohl, Annu. Rev. Phys. Chem. 39, 93 (1988).

[89] M. G. Ghossoub, J.-H. Lee, O. T. Baris, D. G. Cahill, and S. Sinha, Phys. Rev. B 82, 195441 (2010).

[90] H. Harikrishna, S. T. Huxtable, I. B. Shir, S. Kababya, A. Schmidt, D. Dutta, M. Liu, D. Gidley, W. A. Lanford, N. Hellgren, C. Ege, E. Mays, J. Bielefeld, and S. W. King, J. Porous Mater. 27, 565 (2020).

[91] S. N. DiGregorio and S. D. Habermehl, J. Vac. Sci. Technol. A 38, 013404 (2020).

[92] J. Bandet, B. Despax, and M. Caumont, J. Appl. Phys. 85, 7899 (1999).

[93] Y. Itoh, T. Nozaki, T. Masui, and T. Abe, Appl. Phys. Lett. 47, 488 (1985).

[94] D. V. Tsu, G. Lucovsky, and M. J. Mantini, Phys. Rev. B 33, 7069 (1986)

[95] G. Lucovsky, J. Yang, S. S. Chao, J. E. Tyler, and W. Czubatyj, Phys. Rev. B 28, 3234 (1983).

[96] G. Lucovsky, Solid State Commun. 29, 571 (1979).

[97] M. Maeda and H. Nakamura, J. Appl. Phys. 58, 484 (1985).

[98] Z. Yin and F. W. Smith, Phys. Rev. B 43, 4507 (1991).

[99] H. R. Seyf, L. Yates, T. L. Bougher, S. Graham, B. A. Cola, T. Detchprohm, M.-H. Ji, J. Kim, R. Dupuis, W. Lv, and A. Henry, npj Comput. Mater. 3, 49 (2017).

[100] F. DeAngelis, M. G. Muraleedharan, J. Moon, H. R. Seyf, A. J. Minnich, A. J. H. McGaughey, and A. Henry, Nanoscale Microscale Thermophys. Eng. 23, 81 (2018).

[101] L. Isaeva, G. Barbalinardo, D. Donadio, and S. Baroni, Nat. Commun. 10, 3853 (2019).

[102] M. Simoncelli, N. Marzari, and F. Mauri, Nat. Phys. 15, 809 (2019).

[103] J. D. Gale and A. L. Rohl, Mol. Simul. 29, 291 (2003).

[104] P. B. Allen and J. L. Feldman, Phys. Rev. B 48, 12581 (1993).

[105] J. M. Larkin and A. J. H. McGaughey, J. Appl. Phys. 114, 023507 (2013). 